Research Article

\title{
Test and Numerical Study on Monotonic Behavior of Complex CFT Column Joints
}

\author{
Zeliang Yu $\mathbb{D}^{1},{ }^{1}$ Bin Yang $\mathbb{D D}^{1}{ }^{1}$ Bin Jia, ${ }^{2}$ Yuhong Yan, ${ }^{1}$ Shaowen Xiao, ${ }^{1}$ and Ke Lei ${ }^{3}$ \\ ${ }^{1}$ Department of Structural Engineering, Tongji University, Shanghai, China \\ ${ }^{2}$ Sichuan Institute of Building Research, Sichuan, China \\ ${ }^{3}$ China Construction Eighth Engineering Division, Shanghai, China
}

Correspondence should be addressed to Bin Yang; yangbin@tongji.edu.cn

Received 8 May 2019; Revised 17 July 2019; Accepted 22 August 2019; Published 24 September 2019

Academic Editor: Hossein Moayedi

Copyright ( $) 2019$ Zeliang Yu et al. This is an open access article distributed under the Creative Commons Attribution License, which permits unrestricted use, distribution, and reproduction in any medium, provided the original work is properly cited.

\begin{abstract}
This paper presents a test and numerical investigation into the monotonic behavior of three different complex steel trusses to concrete-filled tubular (CFT) column joints. Based on an engineering structure, 1:4 reduced-scale specimens are manufactured and the three-dimensional subassembly testing system is designed to apply the monotonic load. Test phenomena and load-stress curves show that all three types of joints have a considerable load-carrying capacity and joint rigidity. Finite element (FE) analysis is adopted, and the stress distribution shows good agreement with test data. Both test and FE results show that local buckling and yielding in the root region of steel truss are the main failure modes of test joints and the core area of the CFT column remains intact which are in accordance with the design conception of "strong column and weak beam." Design conception of proposed overlap joint form is then investigated based on the FE model, and results show that the optimized overlap joint can effectively reduce the stress concentration in the adjacent steel tube and beam member when compared to the traditional N-type overlap joint. Finally, the influence of the outer diaphragm on the stiffness of joint is analyzed. By comparing the end-displacement of the beam member, conclusion can be obtained that the beam flange thickness is suggested to be chosen as the outer diaphragm thickness. The forms of three different proposed joints and their design conceptions can provide good guidance for designers and engineers.
\end{abstract}

\section{Introduction}

In recent years, composite structures composed of concrete-filled tubular (CFT) columns and steel members are increasingly used in high-rise buildings, large-span buildings, and bridge structures. Experimental researches $[1,2]$ on the mechanical behaviors of CFT columns under different load conditions have been made and proved that the CFT columns have a better bearing capacity, stiffness, and ductility compared to steel columns. Meanwhile, due to the importance of CFT column joints to the whole structures, a series of studies on different CFT column joint forms including through-beam connection to CFT column $[3,4]$, connections using outer diaphragms [5-7], doublesplit tee connections [8], and other types of connections
$[9,10]$ have also been investigated, and results show that these different forms of CFT column joints can be applied in the structural design.

The above research studies mainly focus on the design of two-dimensional in-plane CFT column joints, whether the conclusions obtained can be applied to complex threedimensional CFT column joints is not clear. Also, the current codes [11-13] and the design guide [14] do not present a detailed design method for complex CFT column joints, and the scientific research on the mechanical behavior of complex CFT column joints is much less developed despite the increasing use of composite structures.

Lou et al. [15] presented experimental research on a complex joint composed of steel truss and CFT columns in 
structures of Shanghai Hongqiao station based on a $1: 4$ scale model, and the results show that the joint has a considerable bearing capacity, and all the members are elastic during the whole loading process. Fan et al. [16] tested six three-dimensional joints between CFT columns and composite steel-concrete beams under cyclic load, and the specimens exhibited good strength and stiffness retention capacities. Li et al. [17] tested the steel truss-to-circular CFT column subassembly and concluded that relative strength between steel truss and column zone is the main factor influencing the seismic performance and failure patterns. Besides, researchers also investigated the behavior of other different complex truss joints, i.e., the KK-joint between two welded square hollow section trusses in China National Stadium [18] and various truss joints applied in large-span and heavily-load bridges [19].

However, these complex joint forms were usually different, and the experimental studies mainly focused on the verification of particular engineering structures, so the conclusions were lack of generalization. In addition, few researchers analyzed the design optimization process of complex joints and the influence of detailed strengthen measures, i.e., inner and outer diaphragms. Three different CFT column joints designed in this paper were not investigated before and there is no corresponding design code to follow. Therefore, it is meaningful to investigate the mechanical behaviors of three joints and provide the guidance for the design and application of other similar joints.

The outline of this paper is as follows: Section 1 presents the literature of CFT column joints; Section 2 shows the test program for three complex CFT column joints, including the test specimen, design load case, loading and monitoring scheme, as well as the innovative three-dimensional subassembly test systems; Section 3 presents the test results of three joints under two different load cases, namely the failure mode and stress-strain curves of the joints; Section 4 gives a detailed description of FE modeling and comparison between FE and test results, which further prove the adaptability of the joint design; Section 5 first investigates the support selection to ensure the design load simulation and test operation, and then presents design conceptions of optimized joint form and parameter study on outer diaphragm; and finally, some meaningful conclusions are proposed in Section 6.

\section{Test Program}

2.1. Test Specimens. The test joints are selected from the trans-truss and cantilever-truss regions (Figure 1) which were crucial to the practical structure. Under the similarity conditions of geometry, material, and loading, three different types of specimens (A1, A2, and B1) of reduced-scale $1: 4$ are designed for the test. The 3D models of the joints are shown in Figure 2, and for the convenience of the following description, the steel member and CFT column of each joint are numbered. For joint A1, steel truss and beam member intersect on the CFT column, and inner diaphragms with vertical stiffeners are also used as the strengthening measures of column joint region. Truss members of joint A2 penetrate through the CFT column to improve the tensile bearing capacity. B1 is an in-plane joint, and its bracing members penetrate through the CFT column to strengthen the joint region. Besides, the outer diaphragms are used in all three joints to transfer the external force and reduce stress concentration. The detailed type and dimension of the test joints are listed in Table 1.

2.2. Material Test. The concrete filled in the column of the specimen is C50 concrete, and the average test compressive strength is $44.06 \mathrm{Mpa}$. All the steel members in the specimen are made of Q345B. Tensile tests are performed to investigate the actual mechanical properties of specimens according to the Chinese mechanical testing standard, and a group of three standard tensile coupons is manufactured for each thickness of steel plate, as shown in Figure 3. The average test results of each group are summarized in Table 2, including yield strength, ultimate strength, and elongation, which could be adopted in finite element model.

2.3. Design Loads. Based on the design loads of practical structure, two load combinations LS1 and LS2 are chosen for the test under the most unfavorable condition. This test aims to verify the monotonic behaviors of joints under 2.0-times design loads, and the test loads listed in Tables 3 and 4 are already 2.0-times design loads following the principle of stress equivalent to real joints.

Due to factors such as test environment and loading conditions, the boundary conditions of test joints are different from the actual joints. To facilitate the test operation and test the ultimate bearing capacity of the joint, some of the members are fixed to the reaction frame to provide the reaction force. Figure 4 shows the internal force state and boundary condition of joints A1, A2, and B1, respectively. In the meantime, the secondary internal force is neglected, and the major force that affects the mechanical properties of the joint is considered as the test load. Therefore, the finite element method is adopted to select the reasonable supports, and the detailed analyses will be described in Section 5.1.

2.4. Loading and Monitoring Scheme. To satisfy the loading requirements of the joint specimens and facilitate test operation, the innovative three-dimensional subassembly testing system is designed which includes a special selfbalanced reaction frame in the main plane and a horizontal reaction frame in the secondary plane, as shown in Figure 5. The flange connection is adopted as the fixed end between joint members and reaction frames, and three ranges of $1000 \mathrm{kN}, 2000 \mathrm{kN}$, and $5000 \mathrm{kN}$ hydraulic jacks are used in the test. For A1 and B1 joints, the design loads are mainly compression, so the hydraulic jacks can be directly applied to the members and the moment loads can be applied by eccentric compression. For the A2 joint, a special connector 

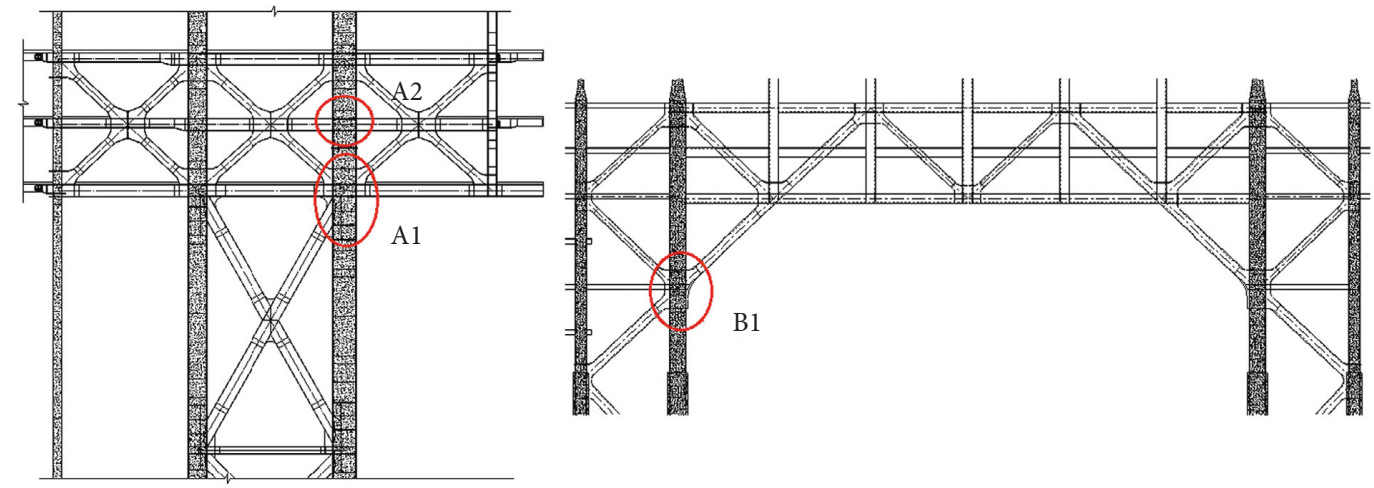

FIGURE 1: Location of selected test joints.

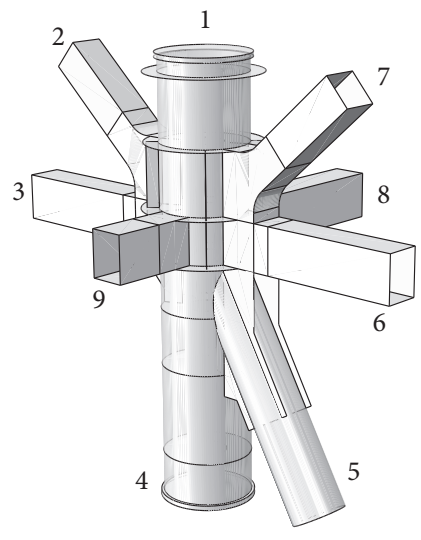

(a)

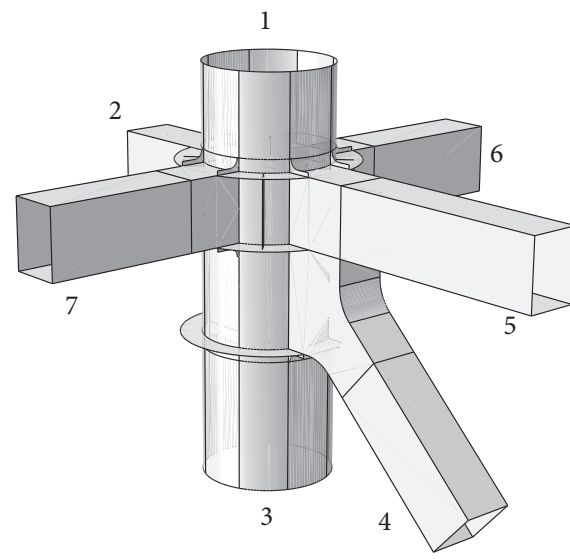

(b)

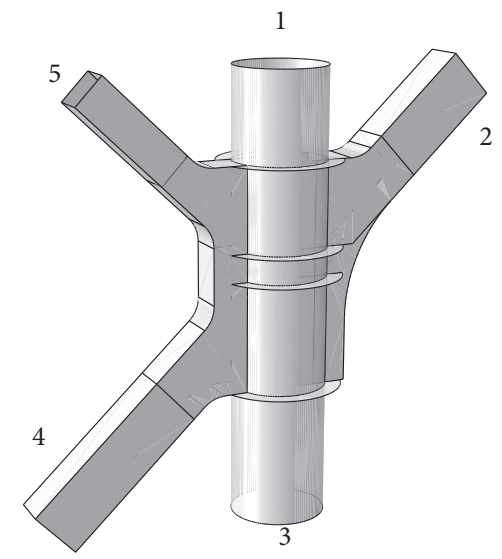

(c)

Figure 2: 3D models of three different joints. (a) A1. (b) A2. (c) B1.

is designed to apply the tensile forces as shown in Figure 5(b).

In order to understand the von Mises stress distribution of the joints, the resistance strain gauges with a gauge factor of 2.0 are used. The strain rosette which composed of three strain gauges is placed on the core area of the CFT column and the potential failure part of the joint. By calculating the strain in $0^{\circ}, 45^{\circ}$, and $90^{\circ}$ direction, the von Mises stress of the joint can be obtained. The detailed layout of the strain rosette is shown in Figure 6, and each number represents a strain monitoring point. As can be seen, there are a total of 62,45 , and 40 strain rosettes placed in A1, A2, and B1 joints separately. The parameters of resistance strain gauges and hydraulic jacks are measured by multichannel modules called Isolated Measurement Pod (IMP) system and linked together to the host computer which controls the IMP system and stores the measured data.

The test loading scheme adopts a monotonous loading method. In order to make the specimen and loading system cooperate well and test the reliability of the instruments, the test starts with a trial loading. In this period, $30 \%$ of the design load is taken for preloading and is equally divided into three steps, maintaining
10 minutes in each load step. The first trial loading step takes into account the gravity and the self-weight of the loading equipment. After loading system and test instruments are examined, the formal loading is started. The formal load step is 0.1-times design load, and the specimens are loaded until 2.0-times design load or until the failure of joints occurs. The loading process is maintained for 10 minutes in each load step, and the strain data are recorded 3 minutes after each load step. During the loading process, when the member of joints appears local buckling or yielding, it can be considered as the failure of joints.

\section{Analysis of Test Results}

3.1. Test Phenomena. During the entire loading process to 2.0-times design load, all joints A1, A2, and B1 appear with no destruction, and all members of the joints remain elastic. In the core area of $\mathrm{A} 1$ and $\mathrm{B} 1 \mathrm{CFT}$ column where the pressure loads are transferred from truss member, the steel pipe wall exhibits no local buckling or deformation. Although the truss members of the A2 joint are mainly subjected to bending moment and tensile force, no separation is found between the pipe wall and the concrete. When 
TABle 1: Type and dimension of specimens.

\begin{tabular}{|c|c|c|c|}
\hline Specimen & $\begin{array}{l}\text { Member } \\
\text { number }\end{array}$ & Section and type & Dimension (mm) \\
\hline \multirow{7}{*}{ A1 } & 1,4 & $\begin{array}{l}\text { Circular CFT } \\
\text { column }\end{array}$ & $\Phi 377 \times 10$ \\
\hline & 2 & $\begin{array}{c}\text { Steel box-shape } \\
\text { brace }\end{array}$ & $\square 150 \times 150 \times 8 \times 8$ \\
\hline & 3,6 & $\begin{array}{c}\text { Steel box-shape } \\
\text { beam }\end{array}$ & $\square 200 \times 150 \times 8 \times 10$ \\
\hline & 5 & $\begin{array}{c}\text { Circular CFT } \\
\text { brace }\end{array}$ & $\Phi 219 \times 6$ \\
\hline & 7 & $\begin{array}{c}\text { Steel box-shape } \\
\text { brace }\end{array}$ & $\square 150 \times 150 \times 5 \times 6$ \\
\hline & 8 & $\begin{array}{c}\text { Steel box-shape } \\
\text { beam }\end{array}$ & $\square 200 \times 150 \times 12 \times 12$ \\
\hline & 9 & $\begin{array}{c}\text { Steel box-shape } \\
\text { beam }\end{array}$ & $\square 200 \times 150 \times 10 \times 10$ \\
\hline \multirow{5}{*}{ A2 } & 1,3 & $\begin{array}{l}\text { Circular CFT } \\
\text { column }\end{array}$ & $\Phi 377 \times 10$ \\
\hline & 2 & $\begin{array}{l}\text { Steel box-shape } \\
\text { beam }\end{array}$ & $\square 200 \times 150 \times 10 \times 12$ \\
\hline & 4 & $\begin{array}{c}\text { Steel box-shape } \\
\text { brace }\end{array}$ & $\square 175 \times 150 \times 10 \times 12$ \\
\hline & 5 & $\begin{array}{c}\text { Steel box-shape } \\
\text { beam }\end{array}$ & $\square 200 \times 150 \times 12 \times 12$ \\
\hline & 6,7 & $\begin{array}{l}\text { Steel box-shape } \\
\text { beam }\end{array}$ & $\square 200 \times 150 \times 8 \times 8$ \\
\hline \multirow{3}{*}{ B1 } & 1,3 & $\begin{array}{l}\text { Circular CFT } \\
\text { column }\end{array}$ & $\Phi 377 \times 10$ \\
\hline & 2,4 & $\begin{array}{c}\text { Steel box-shape } \\
\text { brace }\end{array}$ & $\square 200 \times 150 \times 12 \times 12$ \\
\hline & 5 & $\begin{array}{c}\text { Steel box-shape } \\
\text { brace }\end{array}$ & $\square 150 \times 150 \times 8 \times 8$ \\
\hline
\end{tabular}

external forces reach 2.3-times design load, local buckling occurs in the root region of member 2 of the A1 joint, as shown in Figure 7(a). For the A2 joint, there is no obvious buckling or deformation when external forces reach 2.5times design load. For the B1 joint, local buckling occurs in the root region of member 2 when external forces exceed 2.1times design load as shown in Figure 7(b). However, other truss members of three joints still remain elastic.

During the entire loading process to 2.0-times design load under load case LS2, all joints A1, A2, and B1 also have no destruction, and all members of the joints remain elastic. When external forces reach 2.1-times design load, local buckling occurs in the root region of member 2 of the $\mathrm{B} 1$ joint as shown in Figure 7(c). Other truss members of three joints have no buckling or large deformation, and the steel column also remains intact. In the core area of the A1 and B1 joint where the pressure loads are applied to the truss, no local buckling or obvious deformation appears in the steel pipe wall. The CFT column is cut from the middle of the core area to observe the concrete damage after the test is finished. Results show that the concrete filled in the column appears with no cracking or crushing, and no separation is found between the pipe wall and the concrete.

3.2. Load-Stress Curves. The von Mises stress is usually used as a judgment of plasticity for multidirectional stress state [15]; thus, the load-stress curves are essential for analyzing the mechanical behavior of the joint. Considering the amount of strain rosettes placed on joint area, only one representative monitoring point is selected for each member of the A1 joint, and the load-stress curves are shown in Figures 8(a) and 8(b). Under 2.3times design load case LS1, monitoring point 3 on member 2 shows the highest von Mises stress of $490.06 \mathrm{MPa}$ which already exceeded the yield strength. Moreover, the load-stress curve shows that member 2 entered the plastic stage when load ratio exceeds 2.0, and it is in accordance with test phenomena. However, stress of other monitoring points is all smaller than $350 \mathrm{MPa}$, and the curves are linearly increasing which indicates that all the other steel members of the A1 joint are elastic. The stress of monitoring point 58 in the core area of the column is only $133.33 \mathrm{MPa}$ which proved the extra bearing capacity of CFT columns. Under 2.2-times design load case LS2, von Mises stress of monitoring point 3 also exceeded the yield strength, while other members are still at elastic stage. Results show that the root region of member 2 is the potential failure part of the A1 joint under both load cases.

Similarly, the load-stress curves of the A2 joint are shown in Figures 8(c) and 8(d). Under 2.5-times design load case LS1, the maximum von Mises stress occurs at monitoring point 44 and reaches $383.54 \mathrm{MPa}$ which is smaller than the yielding strength; thus, all the members of A2 joints remain elastic. Under 2.2-times design load case LS2, the von Mises stress at monitoring point 44 and 7 are $413.05 \mathrm{MPa}$ and $386.44 \mathrm{MPa}$, respectively, and they are also smaller than the yielding strength. For both design load cases, the whole A2 joint is at elastic stage which proved the applicability of this joint form.

The B1 joint is a two-dimensional joint mainly bearing in-plane loads. One representative monitor point is selected from each truss member of the B1 joint, and three monitoring points are selected from the CFT column. The loadstress curves of these monitoring points are shown in Figures 8(e) and 8(f). It can be found that under both load cases LS1 and LS2, the maximum stress of monitoring points 1 is higher than the yield strength of $443.83 \mathrm{MPa}$ which means the root region of member 2 reaches the plastic stage. The monitoring point 9 in the connection area between member 4 and CFT column also have a high stress of $420.50 \mathrm{MPa}$ under load case LS1 due to the stress concentration of sharp corner.

3.3. Analysis of Joint Performance. Under 1.0-times design load in two different load cases, steel members and concrete of three joints are elastic and have a low stress level, which indicates the adaptability of joints in structural design. When the load is increased to 2.0-times design load, most of the members are still at elastic stage, only some local parts of the member root region enter the plastic stage, i.e., the root region of member 2 of A1 joints under load case LS1. During the loading process, no obvious buckling or large deformation is observed in these plastic zones which 


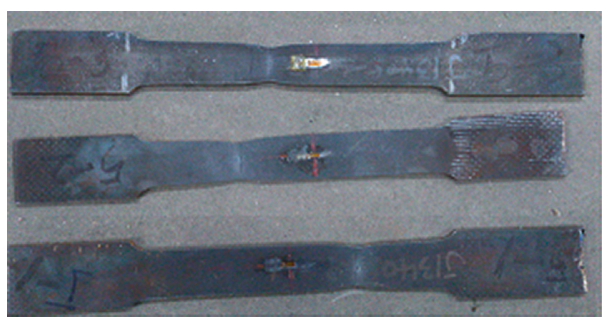

(a)

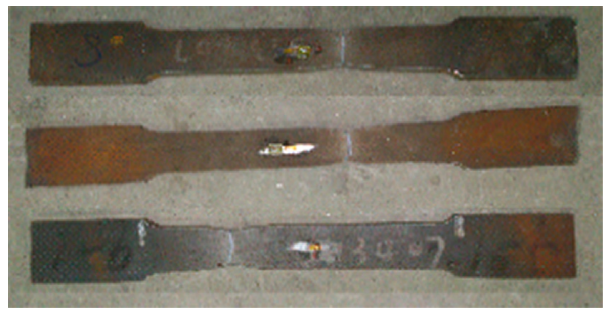

(c)

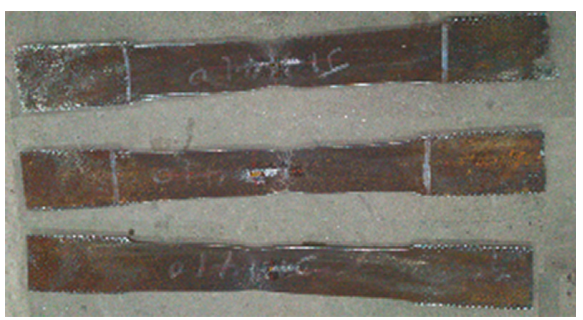

(b)

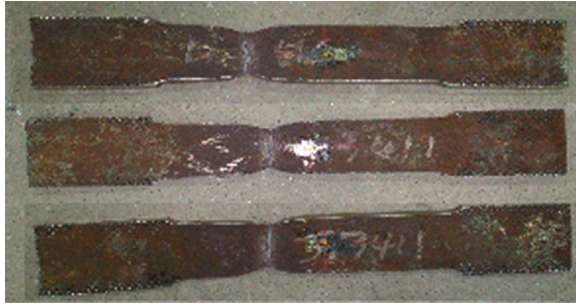

(d)

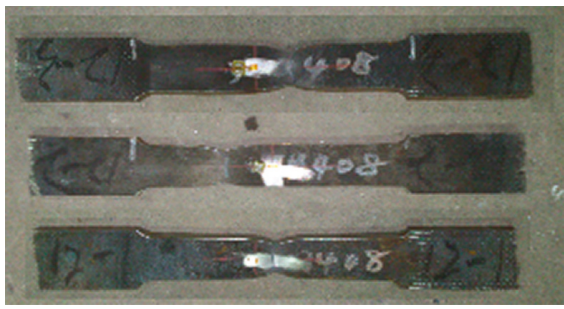

(e)

FIgURE 3: Tensile coupons of steel material: (a) $5 \mathrm{~mm}$. (b) $6 \mathrm{~mm}$. (c) $8 \mathrm{~mm}$. (d) $10 \mathrm{~mm}$. (e) $12 \mathrm{~mm}$.

TABle 2: Material test results.

\begin{tabular}{lccc}
\hline Thickness $(\mathrm{mm})$ & Yield strength $(\mathrm{MPa})$ & Ultimate strength $(\mathrm{MPa})$ & Elongation $(\%)$ \\
\hline 5 & 486.31 & 624.11 & 22.83 \\
6 & 449.07 & 605.47 & 25.90 \\
8 & 456.89 & 568.82 & 22.82 \\
10 & 447.66 & 580.37 & 22.08 \\
12 & 443.83 & 582.20 & 22.13 \\
\hline
\end{tabular}

TABLE 3: Design load case LS1 of testing joints.

\begin{tabular}{ccccccc}
\hline Joints & Member & $\begin{array}{c}N \\
(\mathrm{kN})\end{array}$ & $\begin{array}{c}V_{1} \\
(\mathrm{kN})\end{array}$ & $\begin{array}{c}V_{2} \\
(\mathrm{kN})\end{array}$ & $\begin{array}{c}M_{1} \\
(\mathrm{kN} \cdot \mathrm{m})\end{array}$ & $\begin{array}{c}M_{2} \\
(\mathrm{kN} \cdot \mathrm{m})\end{array}$ \\
\hline \multirow{4}{*}{$\mathrm{A} 1$} & 1 & 3064 & 462 & - & 220 & $\mathbf{2 5 2}$ \\
& 2 & 1324 & - & - & - & - \\
& 3 & 772 & - & - & 70 & - \\
& 7 & 620 & - & - & - & - \\
& 8 & 1232 & - & - & 106 & - \\
\multirow{4}{*}{$\mathrm{A} 2$} & 1 & 1585 & 177 & 325 & 38 & $\mathbf{5 7 0}$ \\
& 4 & 1825 & - & - & - & - \\
& 5 & 865 & 130 & - & 160 & - \\
\hline & 6 & 120 & - & - & 42 & - \\
\hline & 1 & 3375 & - & - & - & - \\
& 2 & 3062 & - & - & - & - \\
& 5 & $\mathbf{5 0 4}$ & - & - & - & - \\
\hline
\end{tabular}

means the joints remain intact, and this proved that these joints have good mechanical performance and bearing capacity. When the applied load exceeds 2.0-times design
TABLE 4: Design load case LS2 of testing joints.

\begin{tabular}{ccccccc}
\hline Joints & Member & $\begin{array}{c}N \\
(\mathrm{kN})\end{array}$ & $\begin{array}{c}V_{1} \\
(\mathrm{kN})\end{array}$ & $\begin{array}{c}V_{2} \\
(\mathrm{kN})\end{array}$ & $\begin{array}{c}M_{1} \\
(\mathrm{kN} \cdot \mathrm{m})\end{array}$ & $\begin{array}{c}M_{2} \\
(\mathrm{kN} \cdot \mathrm{m})\end{array}$ \\
\hline \multirow{4}{*}{$\mathrm{A} 1$} & 1 & 3722 & 678 & - & 264 & $\mathbf{4 0 0}$ \\
& 2 & 1356 & - & - & - & - \\
& 3 & 1224 & - & - & 72 & - \\
& 7 & 916 & - & - & - & - \\
& 8 & 1644 & - & - & 120 & - \\
\hline \multirow{4}{*}{ A2 } & 1 & 1545 & 239 & 420 & 55 & $\mathbf{6 9 5}$ \\
& 4 & 1853 & - & - & - & - \\
& 5 & 1150 & 138 & - & 172 & - \\
\hline \multirow{3}{*}{ B1 } & 6 & 196 & - & - & 65 & - \\
& 1 & 2937 & - & - & - & - \\
& 2 & 3043 & - & - & - & - \\
\hline
\end{tabular}

load, some members of the joints show different levels of buckling. However, these buckling members are all truss members; all the CFT columns of three joints remain intact 


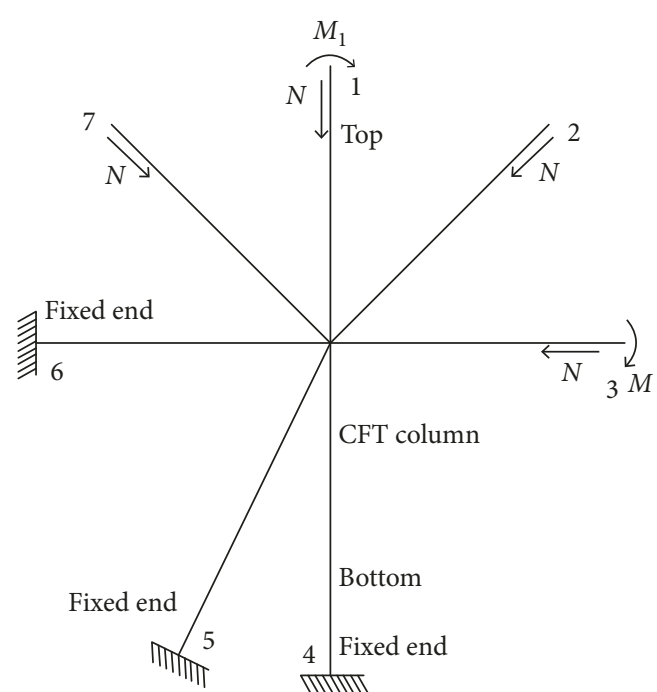

(a)

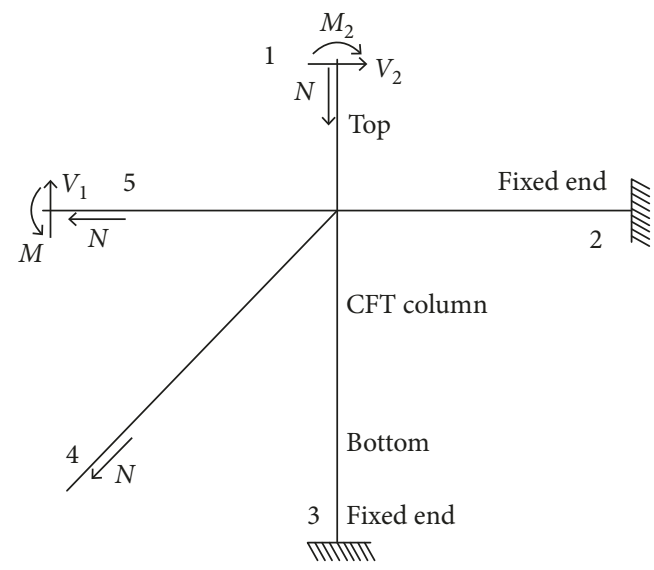

(c)

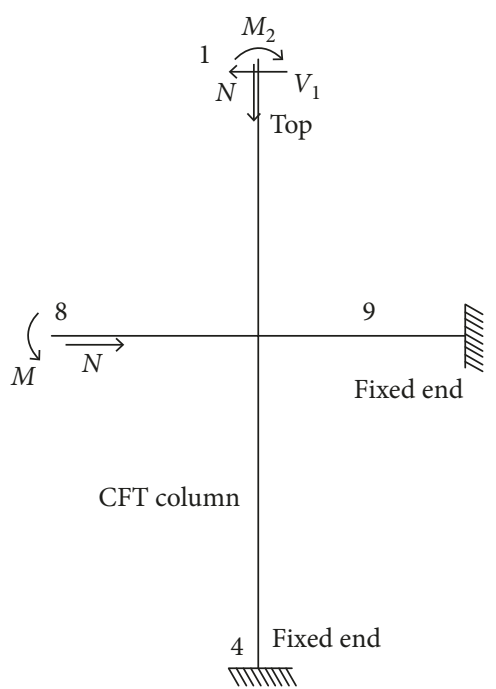

(b)

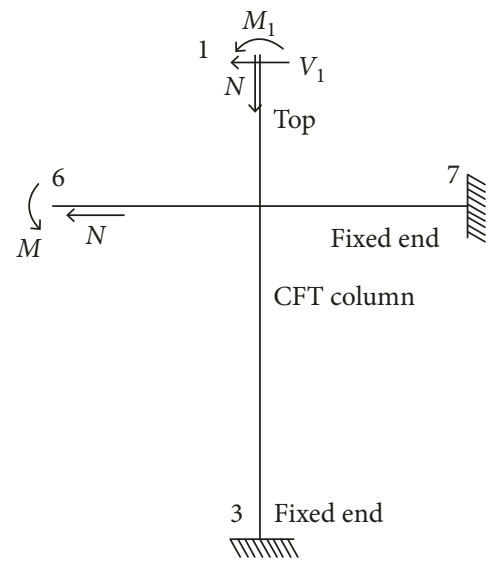

(d)

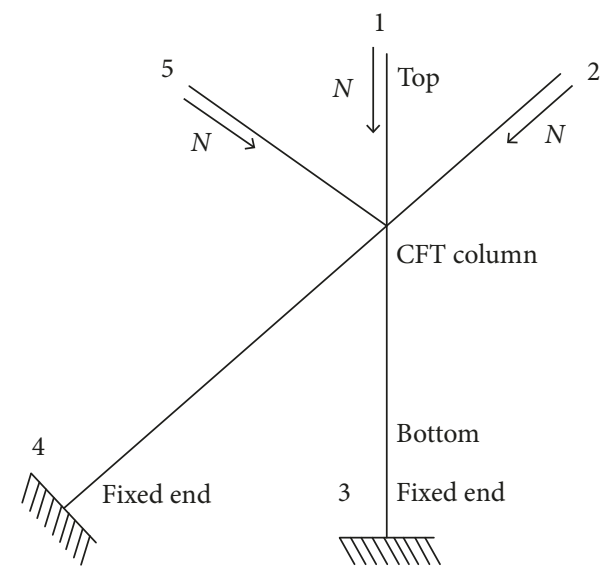

(e)

Figure 4: Internal force state and boundary condition of testing joints. (a) Principal plane of the A1 joint. (b) Secondary plane of the A1 joint. (c) Principal plane of the A2 joint. (d) Secondary plane of the A2 joint. (e) B1 joint.

and have no large deformations. The test phenomena are well consistent with the design conception of "strong column and weak beam" and "strong node and weak member," which further verifies the applicability of these joints in structural design.

\section{Finite Element Analysis}

4.1. Finite Element Model. In addition to the test results, finite element models are also established by using software ABAQUS to further analyze the mechanical performance of 


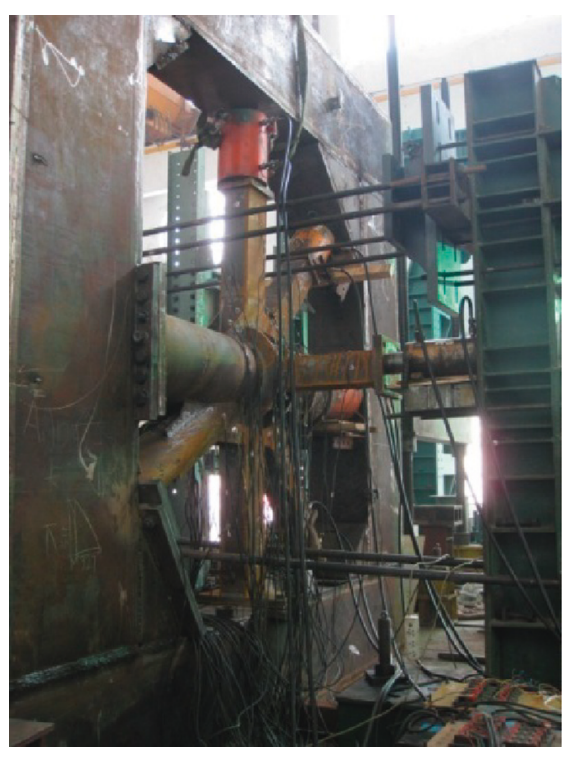

(a)

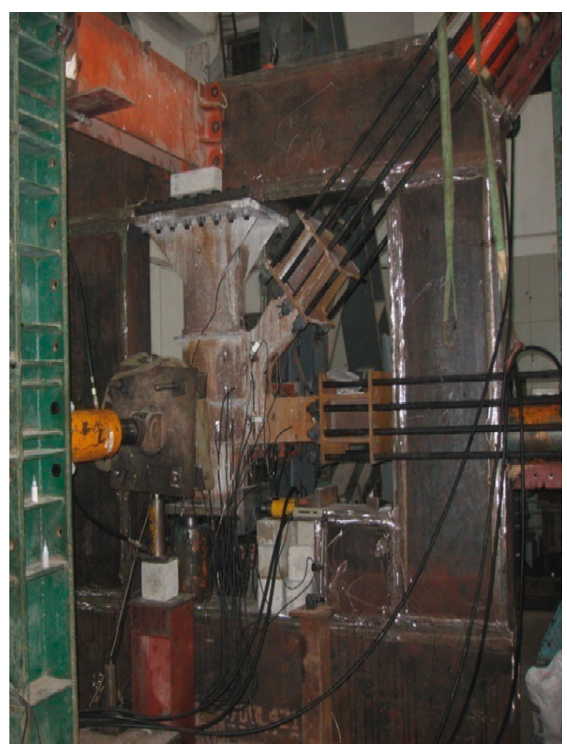

(b)

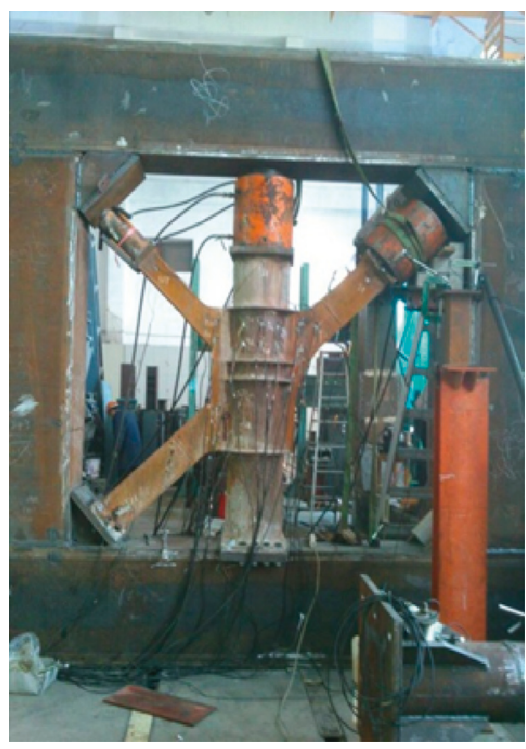

(c)

FIGURe 5: Loading system of CFT column joints. (a) A1 joint. (b) A2 joint. (c) B1 joint.
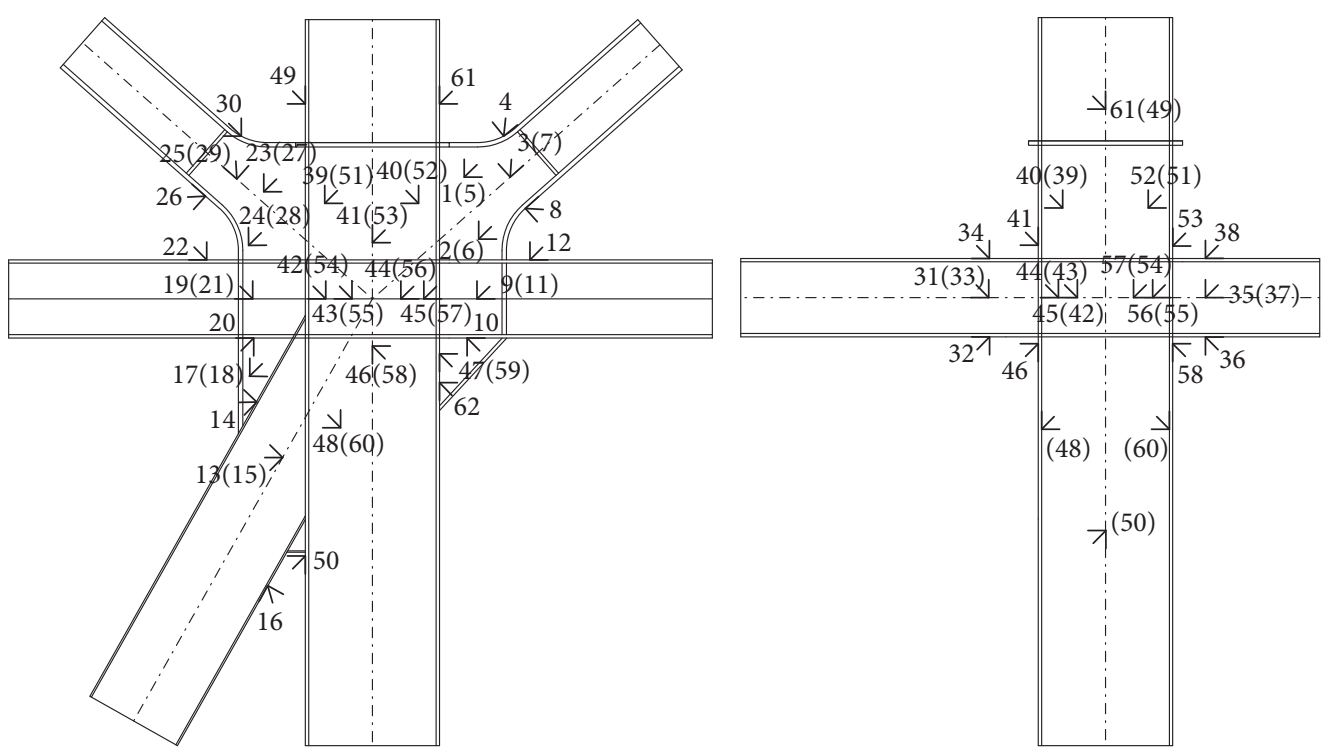

(a)
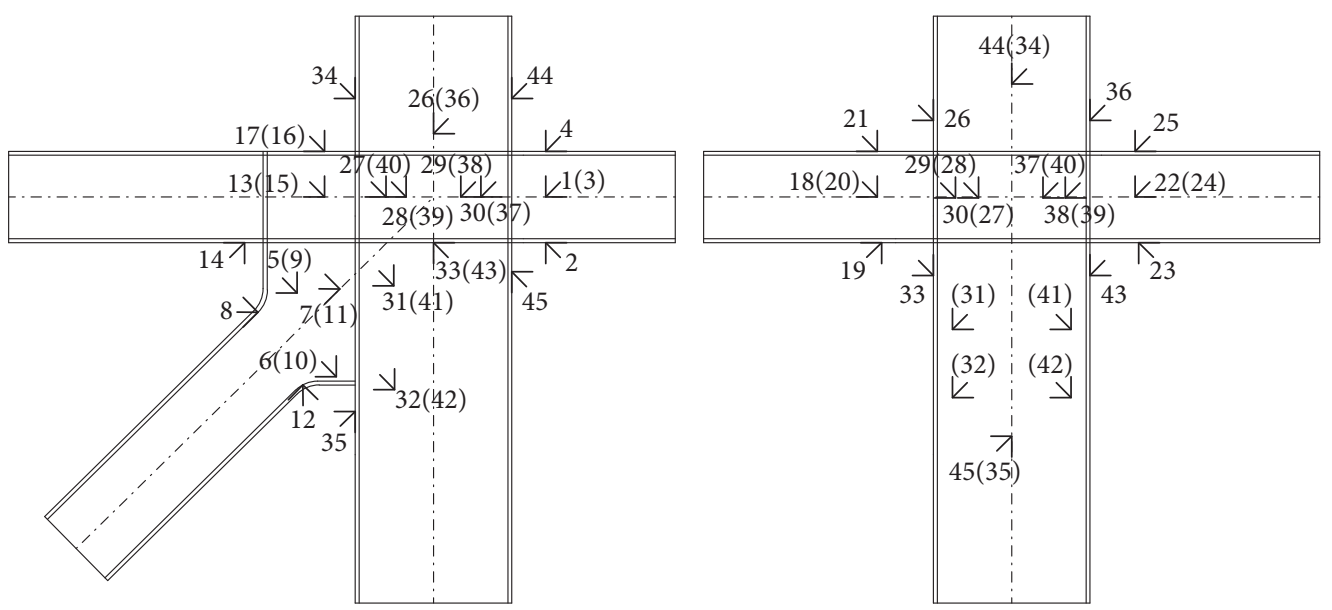

(b)

Figure 6: Continued. 


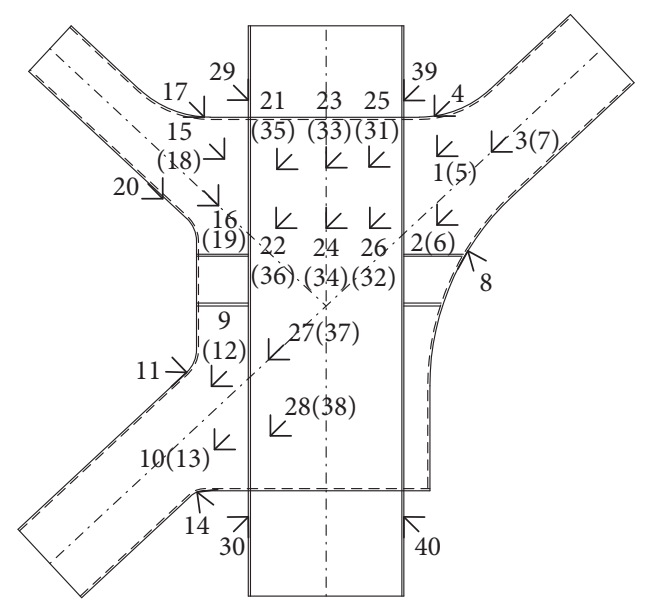

(c)

FiguRe 6: Layout of strain rosettes. (a) A1 joint. (b) A2 joint. (c) B1 joint. (The number in parentheses represents the strain rosette placed on the backside of the member).

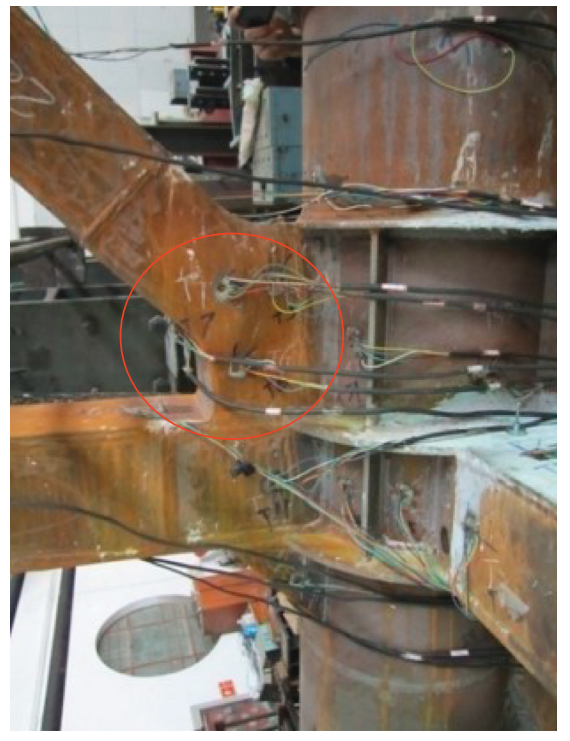

(a)

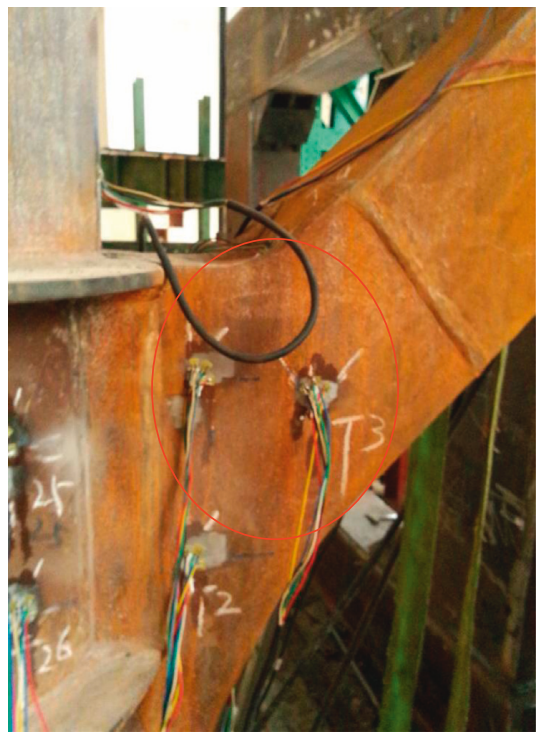

(b)

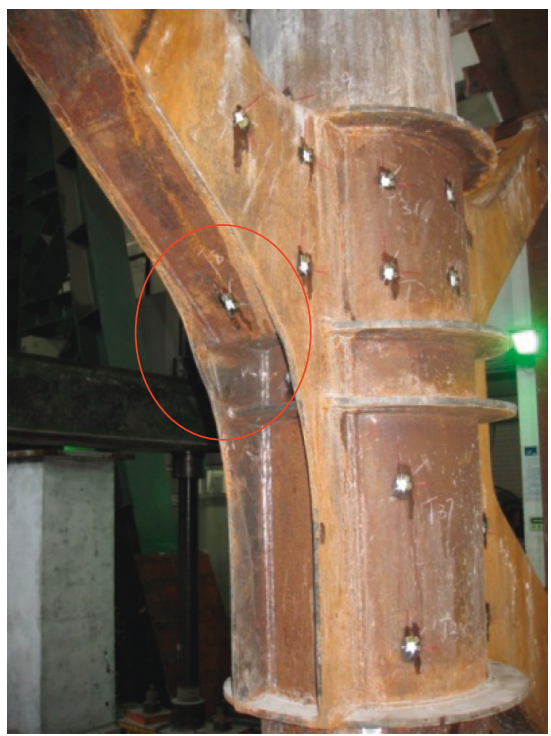

(c)

FIgURE 7: Failure modes of test joints. (a) Local buckling of the A1 joint under load case LS1. (b) Local buckling of the B1 joint under load case LS1. (c) Local buckling of the B1 joint under load case LS2.

three joints under two different load cases, as shown in Figure 9. Steel tube and members are simulated by the elastic-plastic mechanical material model following the von Mises yield criterion and isotropic strengthen theory. Specifically, steel tube and members are supposed to have a Young's modulus of $2.06 \times 10^{5} \mathrm{Mpa}$ and a Poisson's ratio of 0.3 . The yield and ultimate strength are determined by the material test shown in Table 2. Concrete material is supposed to have a Young's modulus of $3.64 \times 10^{5} \mathrm{Mpa}$ and a Poisson's ratio of 0.2 . The concrete model is simulated by damaged plasticity theory which is adopted by other research [1]. Considering the requirements of convergence, accuracy, and computational cost, all steel components are modeled using 4-node shell element S4R, and concrete is modeled using 8-node brick elements C3D8R with three translation degrees of freedom at each node. The general "hard contact" with Coulomb friction is adopted to simulate the contact between the concrete and steel tube, and previous research shows that the friction coefficient between concrete and steel surfaces is almost between 0.2 and 0.6 [20], so a friction coefficient 0.3 is adopted in the FE models.

4.2. Comparisons between Finite Element and Test Results. Finite element results of stress nephogram under load cases LS1 and LS2 are shown in Figure 10. As can be observed, the failure pattern of $\mathrm{A} 1$ and $\mathrm{B} 1$ joints are in accordance with the test phenomena, namely the root region of member 2 occurs local buckling, and member 4 


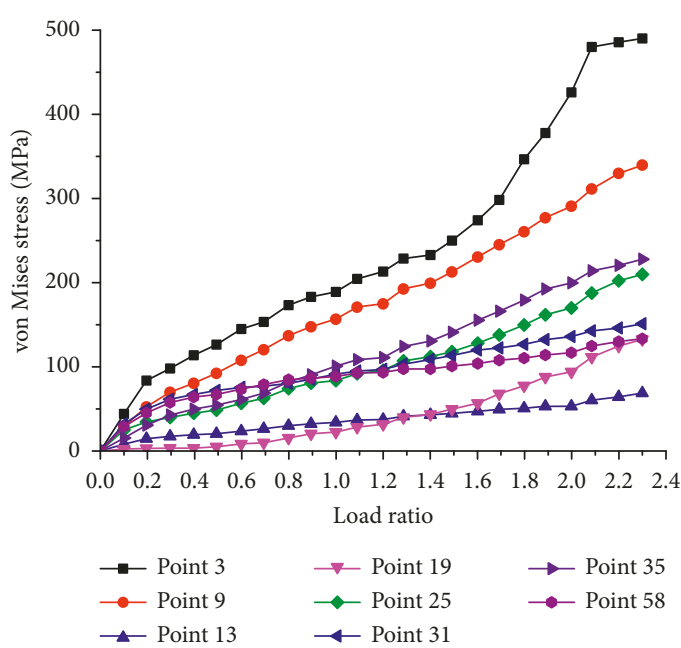

(a)

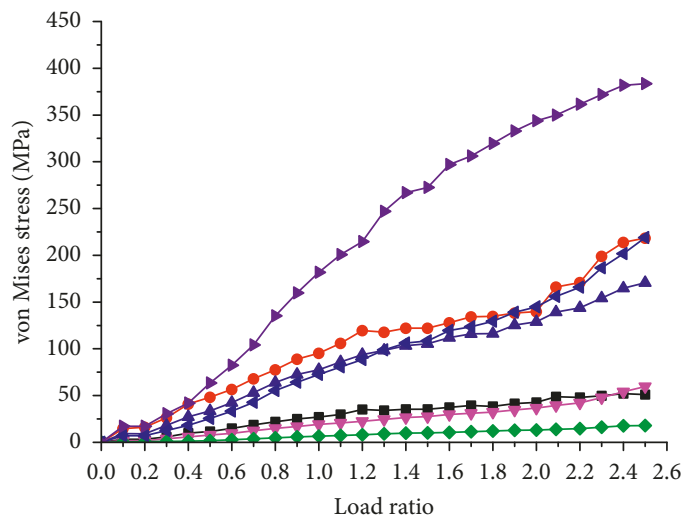

$$
\begin{aligned}
& \rightarrow \text { Point } 4 \\
& \because \text { Point } 7 \\
& \multimap \text { Point } 13 \\
& \rightarrow \text { Point } 20
\end{aligned}
$$

$$
\begin{aligned}
& \longrightarrow \text { Point } 24 \\
& \multimap \text { Point } 30 \\
& \longrightarrow \text { Point } 44
\end{aligned}
$$

(c)

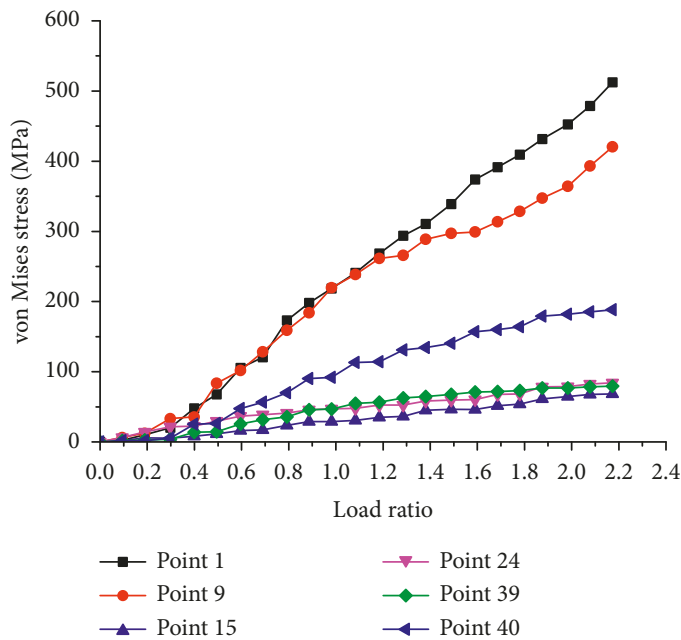

(e)

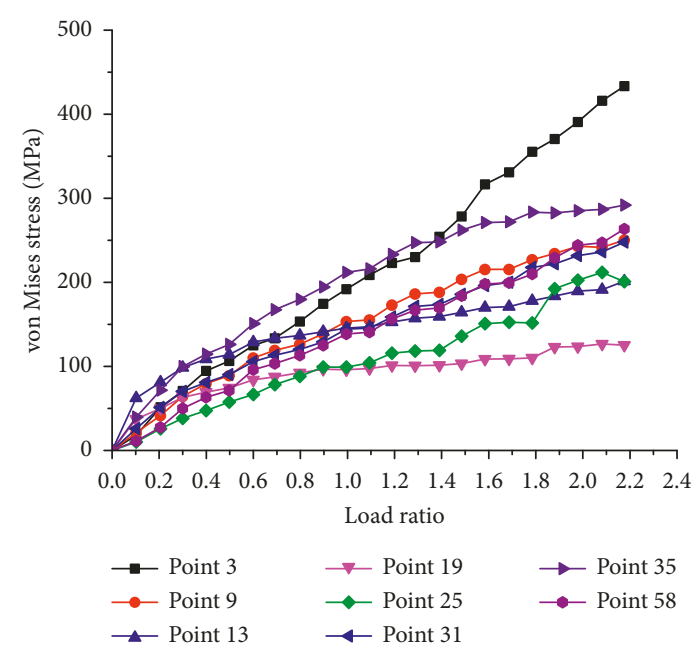

(b)

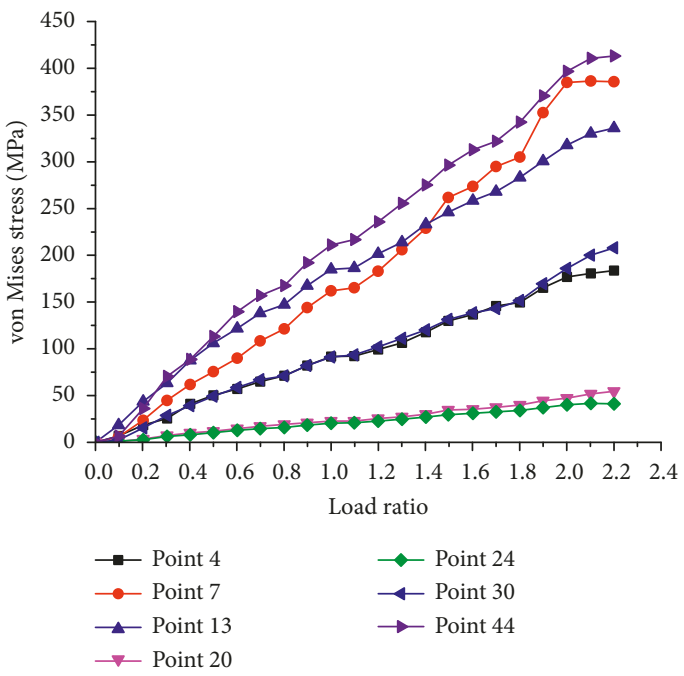

(d)

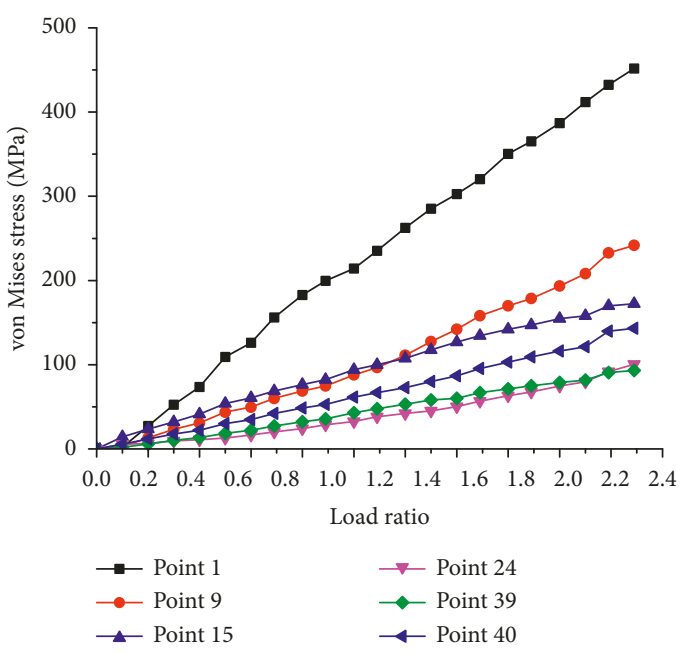

(f)

Figure 8: Load-stress curve of test joints. (a) Load case LS1 of the A1 joint. (b) Load case LS2 of the A1 joint. (c) Load case LS1 of the A2 joint. (d) Load case LS2 of the A2 joint. (e) Load case LS1 of the B1 joint. (f) Load case LS2 of the B1 joint. 


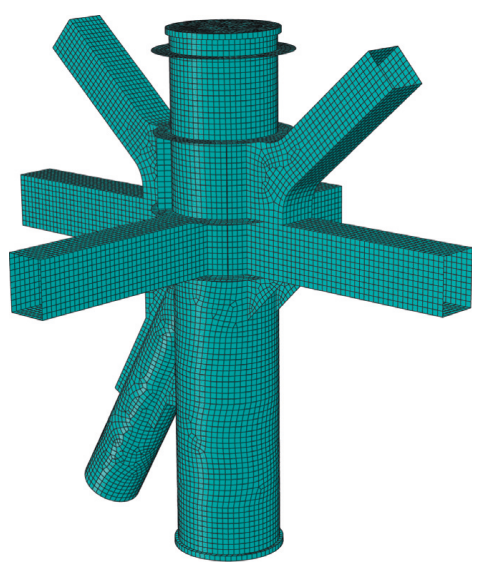

(a)

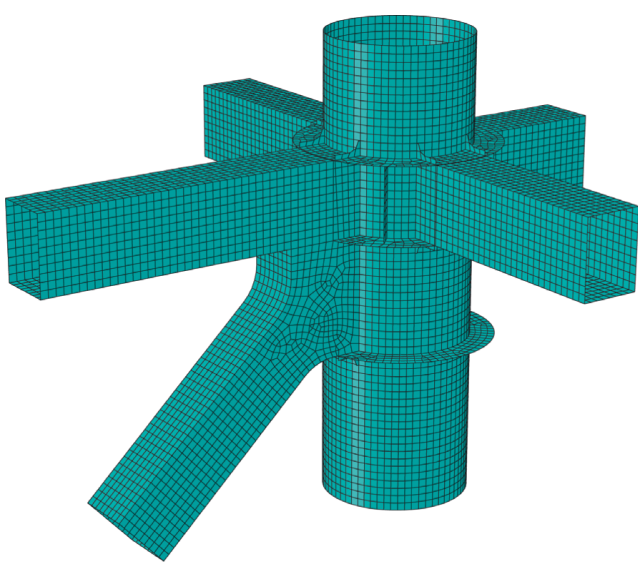

(b)

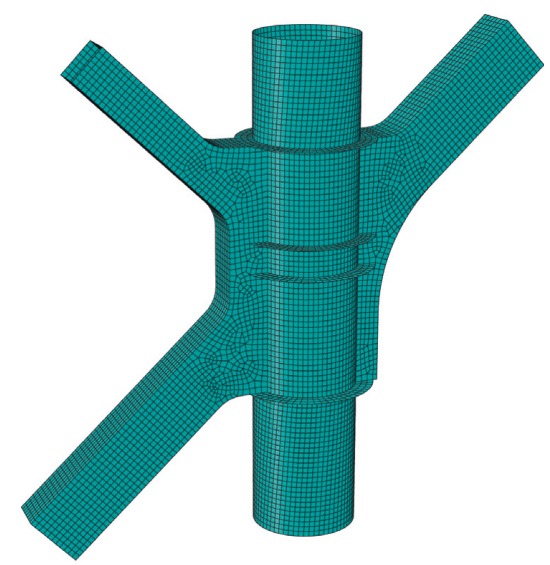

(c)

FIgURE 9: Finite element models of three joints. (a) A1 joint. (b) A2 joint. (c) B1 joint.

S, Mises

SNEG, $($ fraction $=-1.0)$

(Avg: $75 \%$ )

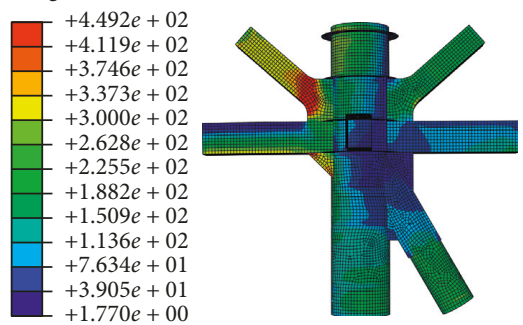

(a)

S, Mises

SNEG, $($ fraction $=-1.0)$

(Avg: 75\%)

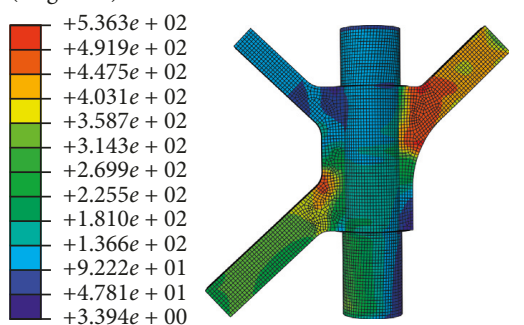

(c)

S, Mises

SNEG, $($ fraction $=-1.0)$

(Avg: 75\%)
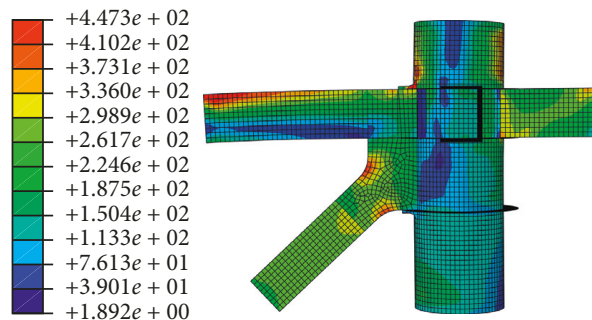

(e)
S, Mises

SNEG, $($ fraction $=-1.0)$

(Avg: $75 \%$ )

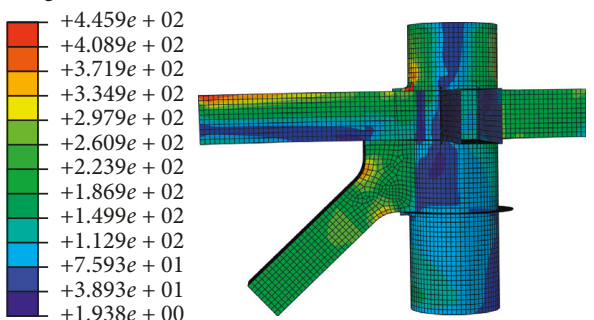

(b)

S, Mises

SNEG, $($ fraction $=-1.0)$

(Avg: $75 \%$ )

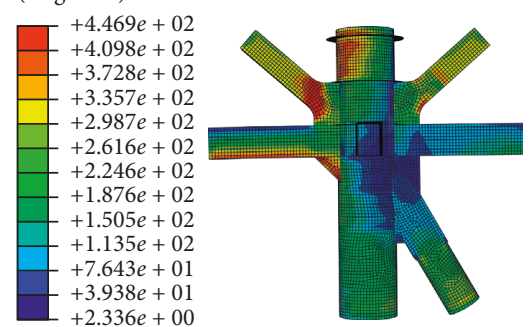

(d)

S, Mises

SNEG, $($ fraction $=-1.0$ )

(Avg: 75\%)

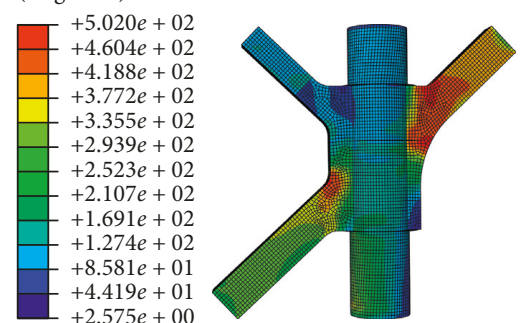

(f)

FIGURE 10: FE results of three joints under load case LS1 and LS2. (a) A1 joint under LS1. (b) A2 joint under LS1. (c) B1 joint under LS1. (d) A1 joint under LS2. (e) A2 joint under LS2. (f) B1 joint under LS2. 


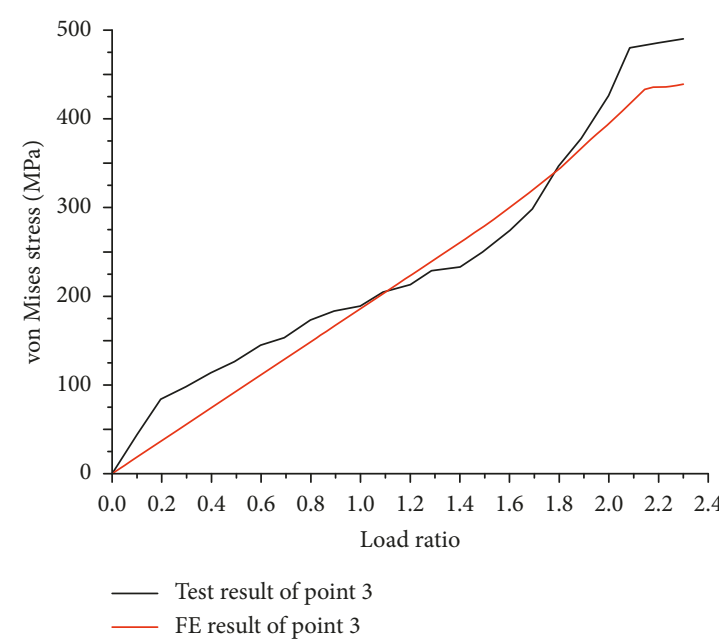

(a)

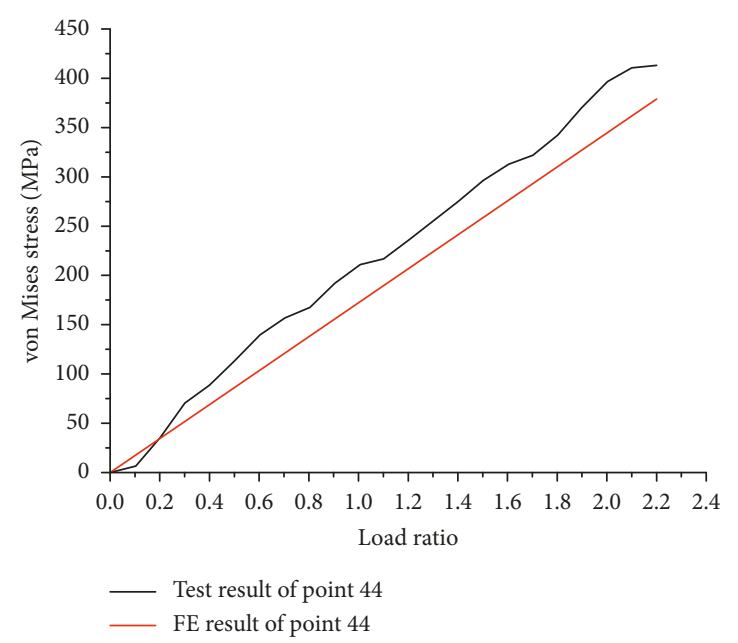

(c)

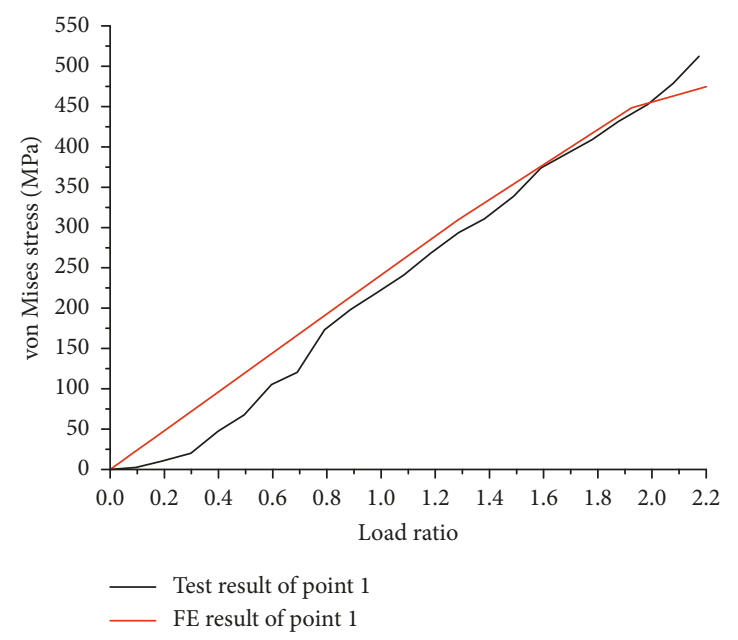

(e)

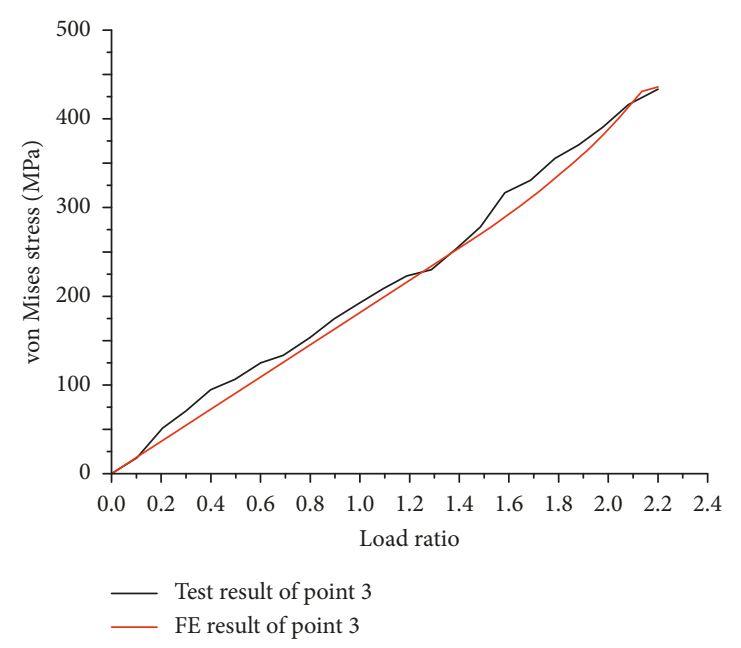

(b)

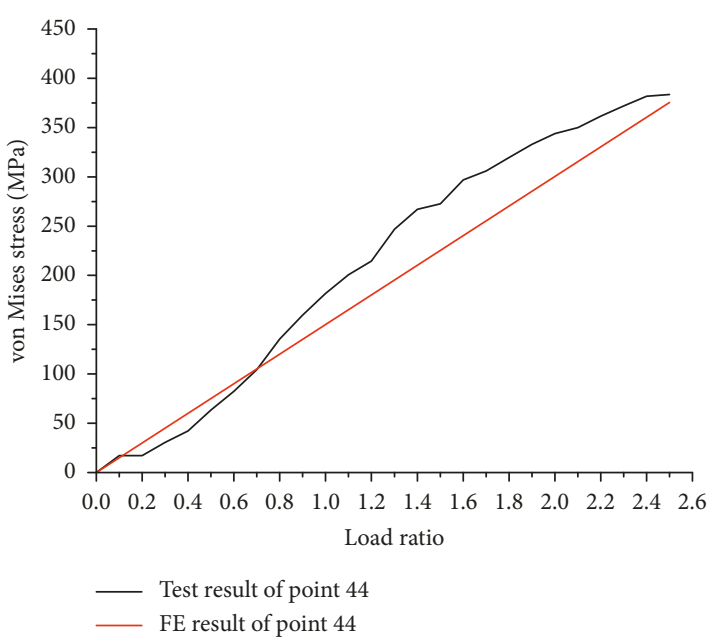

(d)

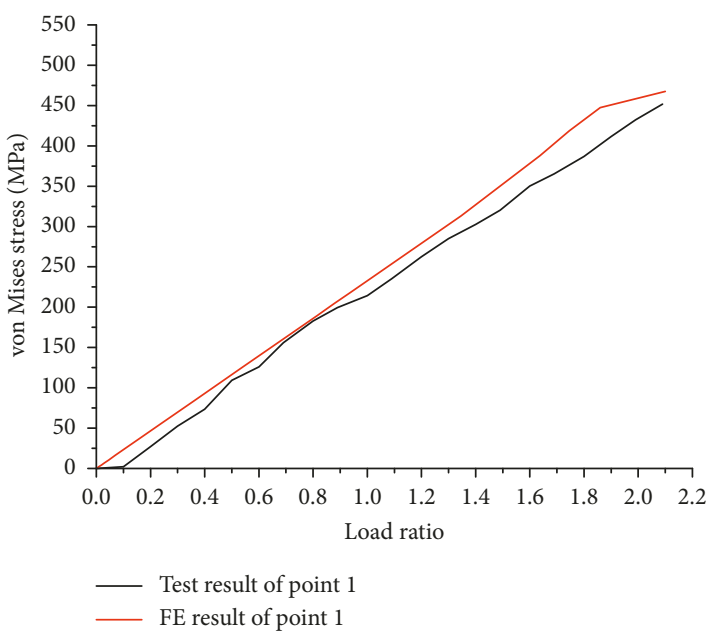

(f)

Figure 11: Comparison between test results and FE results. (a) A1 joint under LS1. (b) A1 joint under LS2. (c) A2 joint under LS1. (d) A2 joint under LS2. (e) B1 joint under LS1. (f) B1 joint under LS2.

of the A2 joint has stress concentration at the corner part. Comparison of test results and FE results for typical monitoring points of three joints are shown in Figure 11.
The stress-load ratio curves of FE results are basically linear and also consistent with the test stress-load ratio curve. 
TABle 5: Stress comparison of the A1 joint.

\begin{tabular}{lccc}
\hline Monitoring point & Test results $(\mathrm{MPa})$ & Finite element results $(\mathrm{MPa})$ & Deviation $(\%)$ \\
\hline 3 & 490.06 & 439.44 & 10.33 \\
9 & 339.49 & 296.24 & 12.74 \\
13 & 68.78 & 60.75 & 11.67 \\
19 & 132.60 & 135.59 & 2.25 \\
25 & 209.86 & 230.79 & 9.97 \\
31 & 151.18 & 138.82 & 8.18 \\
35 & 227.82 & 194.16 & 14.77 \\
58 & 133.33 & 121.56 & 8.83 \\
\hline
\end{tabular}

Considering the complexity of joints and the limitation of paper length, only the detailed results of the A1 joint under load case LS1 are presented. As can be observed, buckling occurs in the root region of member 2 of the A1 joint, which is consistent with the aforementioned test phenomena. After calculation and analysis from Table 5, the average deviation of von Mises stress between FE results and test results is $9.85 \%$. Similarly, the failure modes of other joints can be accurately predicted, and the calculated average deviations of other joints' monitoring points are also in a small range, which indicates good simulation precision of three joints under two different load cases.

Throughout the whole test process, the concrete filled in the column appears with no cracking and crushing. The damage distribution of concrete can also be obtained by finite element analysis. Still taking the A1 joint as an example, the concrete damage distribution under load case LS1 is shown in Figure 12. Stress concentration occurs in the core area where the truss member is connected to the column, and the filled concrete still remains intact, which is consistent with the test phenomena. FE results of other joints can also prove the good performance of the CFT column.

\section{Discussions}

5.1. Support Selection of the A1 Joint. As mentioned before, a special self-balanced reaction frame in the main plane and a horizontal reaction frame-combined system are used in this test. For the A1 joint, a total of seven different steel members are connected to the CFT column (Figure 2(a)), and each member is subjected to different design loads. However, under existing test conditions, it is hard to apply synchronous loads to all members of the joint, and some members of the joint should be fixed on the reaction frame. Although it is more conducive to test operations and controls with more fixed ends, this may cause less accuracy when simulating the real design load case.

To figure out the most suitable number of the fixed ends, FE models with different boundary conditions are investigated under load case LS1. Considering the influence of dead weight and horizontal reaction frame, member 4 and member 9 are set as fixed ends. Four different types of boundary conditions listed in Tables 6-8 show FE results of joint A1 with different boundary type under load case LS1.

It can be seen from Table 7 that under boundary condition of type 1 , the reaction force of member 9 has the

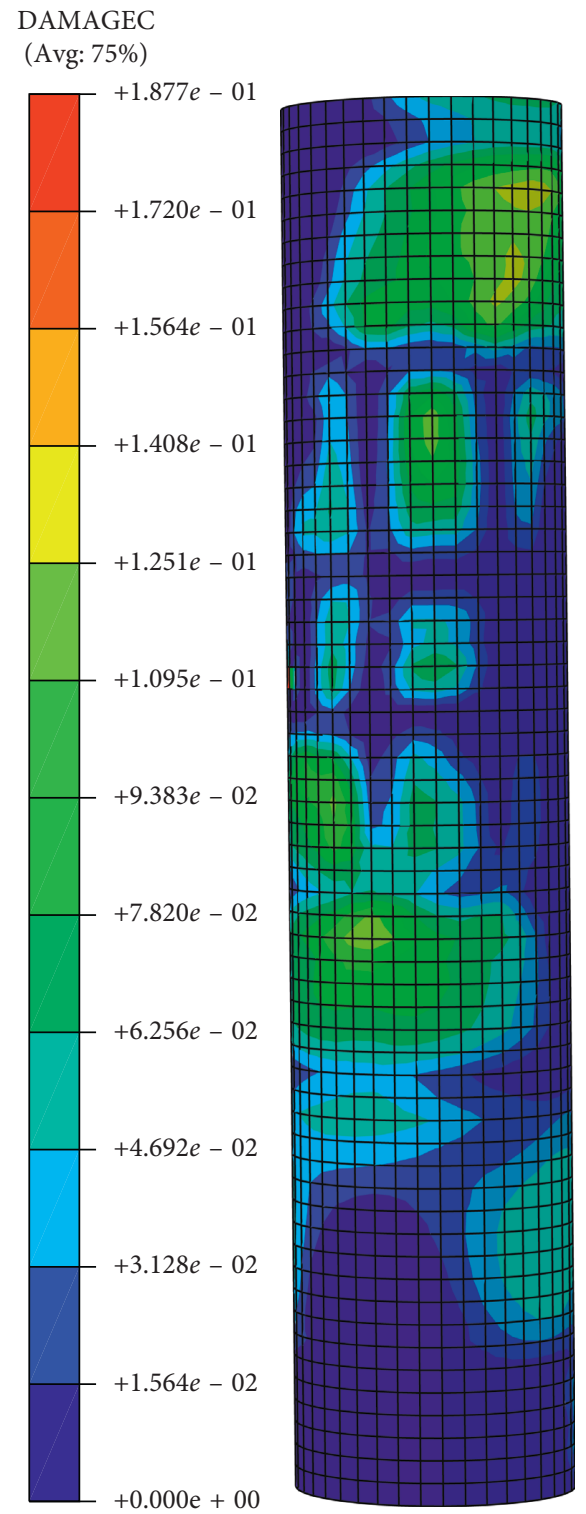

FIgURE 12: Concrete damage distribution of A1 joint under load case LS1.

TABLE 6: Boundary conditions.

\begin{tabular}{lcc}
\hline Type number & Member with fixed end & Member with load end \\
\hline 1 & $4,5,6,9$ & $1,2,3,7,8$ \\
2 & $3,4,5,9$ & $1,2,6,7,8$ \\
3 & $4,5,6,7,9$ & $1,2,3,8$ \\
4 & $3,4,5,6,9$ & $1,2,7,8$ \\
\hline
\end{tabular}


TABLE 7: Support reaction force calculated under different boundary types.

\begin{tabular}{|c|c|c|c|c|c|}
\hline Member number & Design load value $(\mathrm{kN})$ & Type $1(\mathrm{kN})$ & Type $2(\mathrm{kN})$ & Type $3(\mathrm{kN})$ & Type $4(\mathrm{kN})$ \\
\hline 3 & 772 & - & 321 & - & 162 \\
\hline 4 & 3774 & 3684 & 3620 & 3280 & 3458 \\
\hline 5 & 654 & 636 & 568 & 780 & 520 \\
\hline 6 & 976 & 831 & - & 656 & 125 \\
\hline 7 & 620 & - & - & 12 & - \\
\hline 9 & 554 & 445 & 720 & 582 & 580 \\
\hline
\end{tabular}

TABLE 8: Support reaction moment calculated under different boundary types.

\begin{tabular}{lccccc}
\hline Member number & Design load value $(\mathrm{kN} \cdot \mathrm{m})$ & Type $1(\mathrm{kN} \cdot \mathrm{m})$ & Type 2 $(\mathrm{kN} \cdot \mathrm{m})$ & Type 3 $(\mathrm{kN} \cdot \mathrm{m})$ & Type $4(\mathrm{kN} \cdot \mathrm{m})$ \\
\hline 3 & 70 & - & -74 & 63 & - \\
4 & $226 / 298$ & $156 / 243$ & $35 / 152$ & $124 / 201$ & 15 \\
5 & 17 & 13 & - & 26 & 13 \\
6 & 48 & 32 & - & 0 & 27 \\
7 & 0 & - & 75 & 66 & 72 \\
9 & 60 & 55 & & - \\
\hline
\end{tabular}

largest deviation of $19.6 \%$, and other support reaction forces are almost the same as design values. For other types of boundary condition, the largest deviation is more than $50 \%$ and the support reaction forces cannot represent the design values. Table 8 shows that reaction moments of joint A1 under boundary condition of type 1 are close to the design load values, while those under other boundary conditions have large deviations. Thus, considering the feasibility of test operation and the accuracy of test results, the boundary condition of type 1 is selected in this test.

5.2. Discussion of Joint Failure. As can be observed from test results and finite element results, the main failure pattern of $\mathrm{A} 1$ and $\mathrm{B} 1$ joints is local buckling in the root region of truss member 2 when exceeding 2.0-times design load. For both $\mathrm{A} 1$ and $\mathrm{B} 1$ joints, the top of truss member 2 is subjected to axial loads and the boundary conditions are free. So, regardless of different joint structure, the force state of truss member 2 will not change under axial loading. In addition, the truss member 2 of the A1 joint is connected to the CFT column and outer diaphragms, and the webs of truss member 2 of the B1 joint penetrate through the CFT column. Both connections between truss member 2 and CFT column can be considered as fixed connections. So the mechanical analysis model of truss member 2 can be simplified as an axial compression member.

To verify the correctness of simplified mechanical analysis model, all other forces are removed and only axial force of member 2 is applied on the FE model of the A 1 joint under 2.3-times design load of LS1. FE results are shown in Figure 13, and the stress nephogram of member 2 are almost the same as that shown in Figure 10(a).

Researchers have investigated the local buckling of rectangular hollow section members [18, 21, 22], and member 2 can be divided into three parts: upper part, transition region, and root region. For the upper part of truss member 2 with box section, the axial bearing capacity can be calculated by the

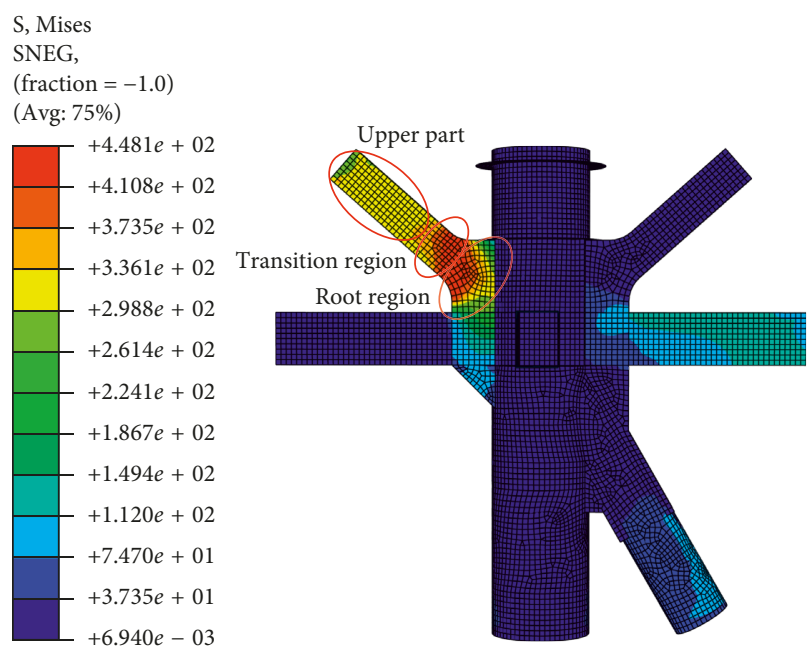

Figure 13: FE results of the A1 joint.

Code for Design of Steel Structures [23], and equations (1)-(5) should be considered in the designing stage:

(1) Section strength:

$$
\sigma_{1}=\frac{N}{A} \leq f_{\mathrm{y}}
$$

(2) Overall stability:

$$
\begin{gathered}
\sigma_{2}=\frac{N}{\varphi A} \leq f_{\mathrm{y}}, \\
\varphi=\frac{1}{2 \lambda_{n}^{2}}\left[\left(0.965+0.300 \lambda_{n}+\lambda_{n}^{2}\right)\right. \\
\left.-\sqrt{\left(0.965+0.300 \lambda_{n}+\lambda_{n}^{2}\right)^{2}-4 \lambda_{n}^{2}}\right],
\end{gathered}
$$




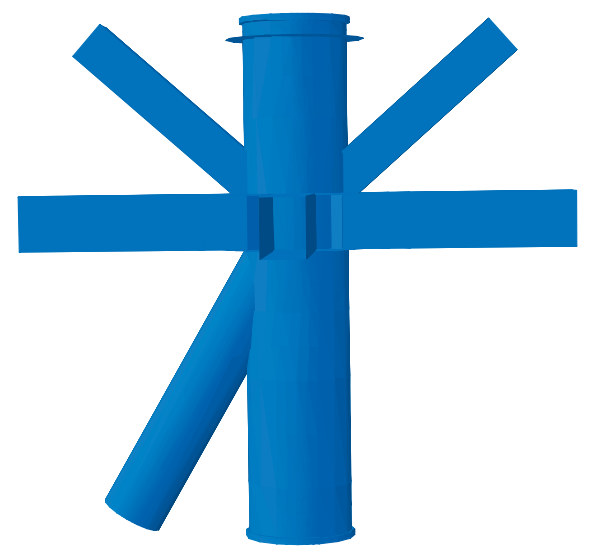

S, Mises

SNEG, $($ fraction $=-1.0)$

(Avg: $75 \%$ )
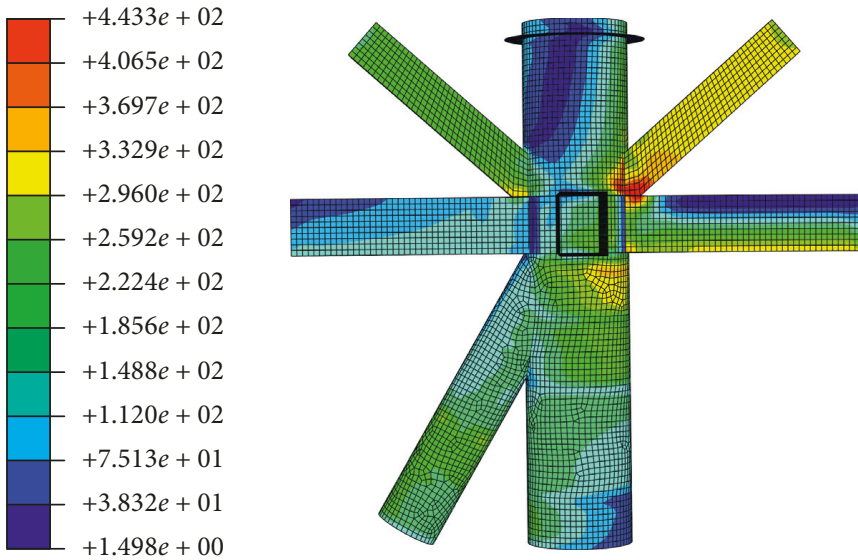

(a)

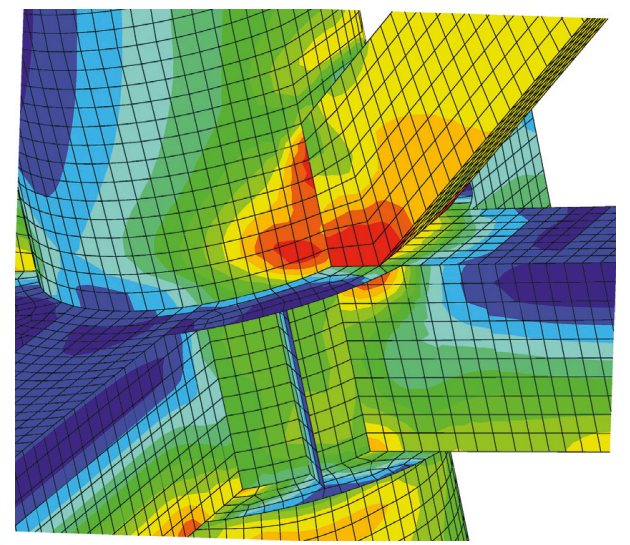

DAMAGEC

(b)

(Avg: $75 \%)$
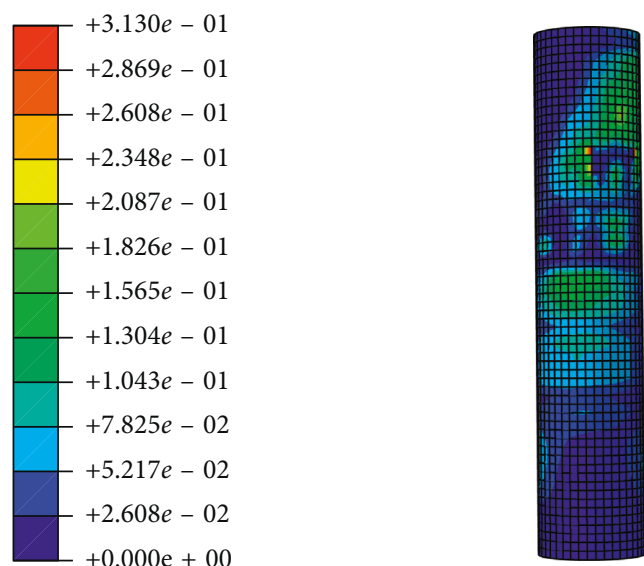

(c)

(d)

Figure 14: FE model and results of overlap joint A1. (a) Design of the overlap joint. (b) FE results. (c) Stress distribution of the overlap part. (d) Concrete damage distribution.

$$
\lambda_{n}=\frac{\lambda}{\pi} \sqrt{\frac{f_{\mathrm{y}}}{E}} .
$$

(3) Local buckling:

$$
\frac{b}{t} \leq 40 \sqrt{\frac{235}{f_{\mathrm{y}}}} .
$$

As is verified by test results and finite element results, theoretical calculation can ensure both upper parts of truss member 2 of joints $\mathrm{A} 1$ and $\mathrm{B} 1$ are in elastic stage, and the overall instability and local buckling will not occur during the whole loading process.

For the transition region of truss member 2, because the flange has a sharp corner in the transition region, local depression occurs in the corner of the flange. The stress in the flange also redistributes and thus causes the stress concentration on the web. According to FE results, the highest stress in the web is $448 \mathrm{MPa}$, which almost reaches the yielding stress.

For the root region of truss member 2, there are no theoretical methods to calculate the bearing capacity or the local buckling load. However, the width-thickness ratio $(b / t)$ is the main factor determining the local buckling, and thus, local buckling failure can be explained by mechanical theory. Considering the web plate of the truss member, when the axial force is transferred from the transition region to the root region, the stress will be transferred to the effective width [14], that is, perpendicular to axial force, which is larger than the web width of the truss member. Therefore, the width-to-thickness ratio of the steel plate will increase obviously in the root region, and the local buckling is more likely to occur. 
For engineer structure under 2.0-times design load, the proposed joint type is already suitable. However, when encountering a larger design load case, further design optimizations are required to increase the bearing capacity. For example, because the sharp corner in transition region can cause stress concentration in the web, inner stiffeners can be added to ensure the force transfer of the flange. The thickness of the steel plate in the root region of member 2 should be increased to avoid the occurrence of local buckling.

\subsection{Design Conception}

5.3.1. Overlap Joint Form of the Truss and Beam Member. For the A1 joint, seven different steel members are connected to the CFT column, and the forces of each joint member are transferred to the CFT column, so the selection of overlap form of adjacent members is of great importance for joint design. In this paper, the design and optimization procedure of the overlap joint form can be divided into the following three parts:

(1) Some research studies [24, 25] have analyzed the mechanical properties of different truss joint types, and the overlapping form is first designed according to Eurocode 3 Design of Steel Structures [11] and CIDECT Design Guide [13], which provide a design method for N-type overlap joint of hollow section truss joints. Figure 14(a) shows the FE model of preliminary joint design form, and the overlap rate is more than $25 \%$ to ensure the force transfer of the weld. Then the FE model is analyzed under 2.0-times design load case LS1, and the whole FE results are shown in Figure 14(b), and the detailed stress distribution of the overlap part is shown in Figure 14(c). It can be noted that the overlap part of truss member 2 produces a high stress value of $443.3 \mathrm{MPa}$ due to stress concentration. The stress concentration also occurs in the steel tube wall near truss member 2 . Although filled by concrete, FE results show that the steel tube wall has large local depression around the truss member. Moreover, the overlap part of member 3 has significant local buckling, as shown in Figure 14(c), and the stress at the corner part almost reaches the yielding strength. The concrete damage distribution is shown in Figure 14(d), as can be seen, the concrete damage occurs in the connection region of truss member 2 which may cause local depression of the column.

(2) Obviously, the preliminary joint form is not suitable for this engineering design. Tong et al. [18] presented the experimental study on KK-joint between two welded square hollow section trusses in China National Stadium. In their research, the truss member was divided into three parts as described in Section 5.2 and concluded that local enlargement at the ends of the truss member can improve force transfer path and decrease the stress concentration. Based on the above analysis, the optimized overlap joint is carried out and presented in Figure 15(a). First, the root region of member 2 is changed to the rectangle shape, which can effectively reduce the stress concentration in the overlap part of the previous design connection. The contact area between member 2 and CFT column is also increased to avoid stress concentration and local compression, and the symmetry design of joint shape ensures the force effectively transferred to the core area. At last, the stiffeners are added below the horizontal members 3 and 6, which can optimize the force transferring path and reduce the local stress of column around the outer diaphragm. However, as can be seen from Figure 15(b), stress concentration occurs in the sharp corner of transition region. The highest von Mises stress is $470 \mathrm{Mpa}$ and it already exceeds the yield strength. To reduce the stress concentration in the transition region, the sharp corner is then optimized to the round corner and the influence of different fillet radii is investigated.

(3) Three different fillet radiuses of $75 \mathrm{~mm}, 100 \mathrm{~mm}$, and $125 \mathrm{~mm}$ are further analyzed. The optimized joint form is simplified according to the description in Section 5.2, and the shell edges connected to the CFT column and the beam member are set as the fixed end, and the upper part of the truss member is neglected, only transition and root part are modeled as shown in Figure 16(a). The FE result of stress nephogram under 2.0-times design load case LS1 is shown in Figures 16(b)-16(d). As can be seen, the stress concentration decreases with the increase of fillet radius, and the stress distribution in the transition region is more uniform for the fillet radius $125 \mathrm{~mm}$.

The final optimized joint form is shown in Figure 17(a) which is the same as test specimen, and Figure 17(b) shows the corresponding stress nephogram under 2.0-times design load. It can be found that no local compression or stress concentration occurs in the column and the overlap part of the truss member, which proves the adaptability of the optimized joint form. The A2 joint looks the same as the A1 joint except for the upper two bracing members, but the members of the A2 joint are subjected to tensile axial forces (Figure 4) which is totally opposite from the A1 joint. Members 4 and 5 of the A2 joint also have the overlap part, and FE models are established to find out the suitable connection form. Figure 17(c) shows the FE results of the A2 joint with member 4 directly connected to member 5 and column. As can be observed from the figure, stress concentration also occurs in the sharp corner of the overlap part. Furthermore, the tube wall has obvious deformation and tends to separate from the concrete. Figure 17(d) shows the $\mathrm{FE}$ results of the A2 joint with optimized member connection form, and it can be found that the optimized connection form of a rectangle plate with a round corner can reduce the stress concentration and improve the tensile bearing capacity. This kind of connection form between truss members is also suitable for combination cases of both 


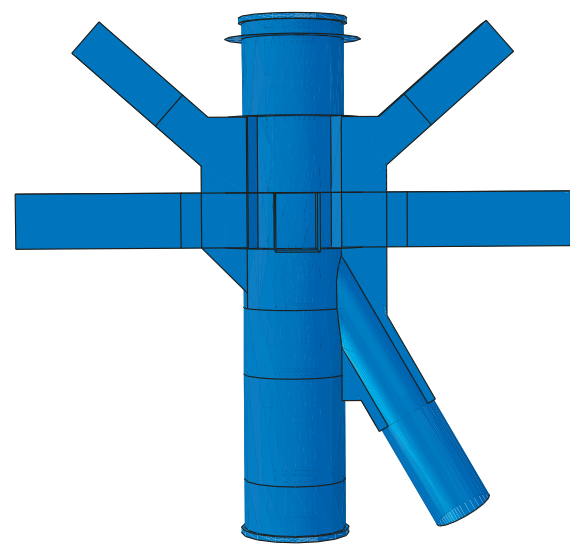

S, Mises

SNEG, $($ fraction $=-1.0)$

(Avg: $75 \%$ )
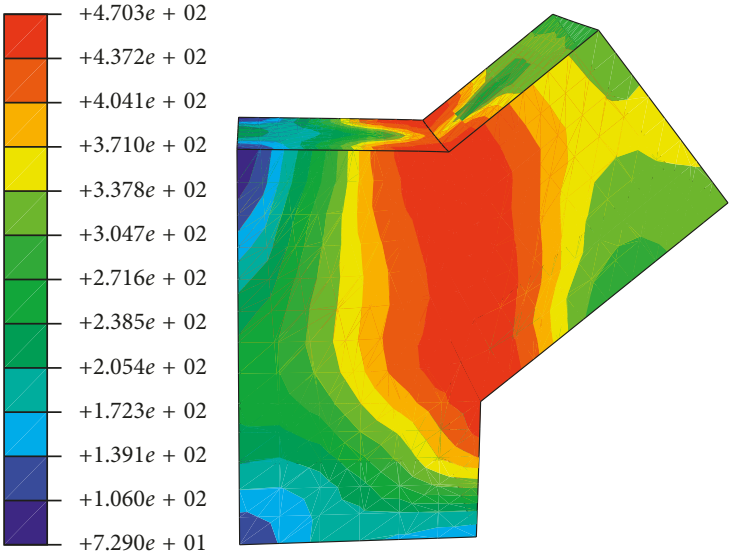

(a)

(b)

Figure 15: FE model of optimized joint form. (a) First optimized joint form (b) Stress concentration in joint region.

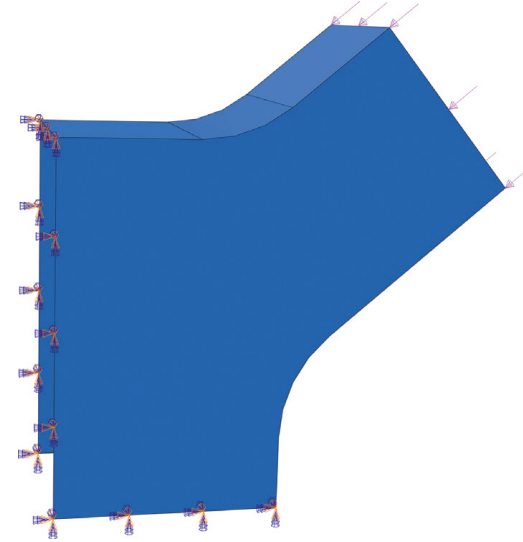

(a)

S, Mises

SNEG, $($ fraction $=-1.0)$

(Avg: $75 \%$ )
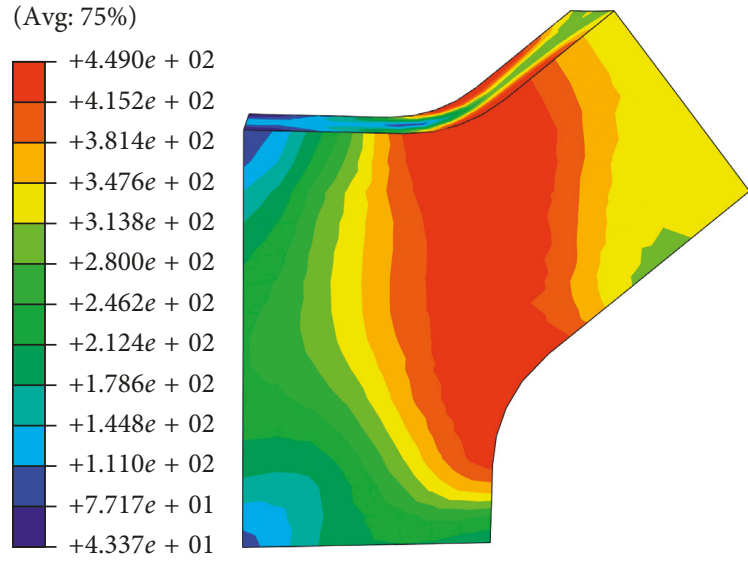

(c)
S, Mises

SNEG, $($ fraction $=-1.0)$

(Avg: $75 \%$ )
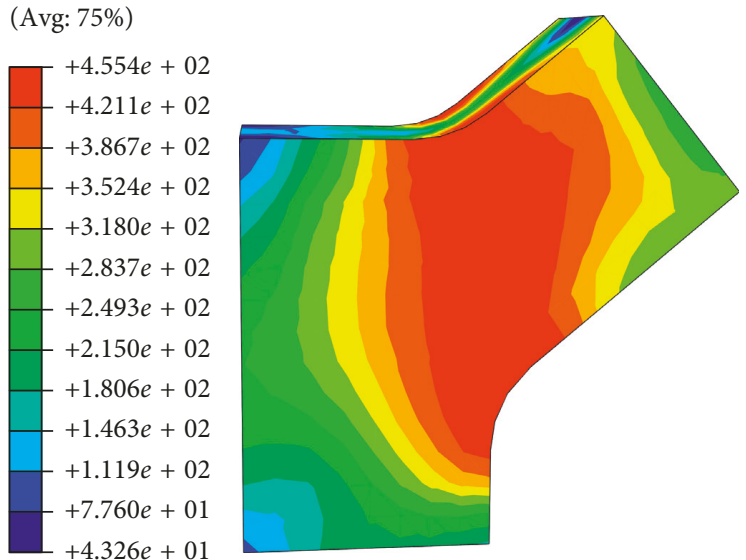

(b)

S, Mises

SNEG, (fraction $=-1.0)$

(Avg: $75 \%$ )
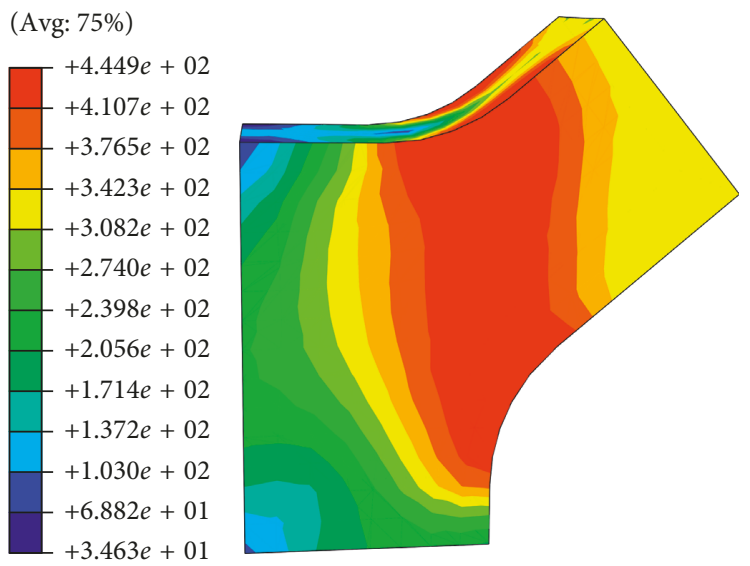

(d)

FIgURE 16: Stress nephogram of different fillet radii. (a) Simplified joint form (b) Fillet radius $=75 \mathrm{~mm}$. (c) Fillet radius $=100 \mathrm{~mm}$. (d) Fillet radius $=125 \mathrm{~mm}$. 


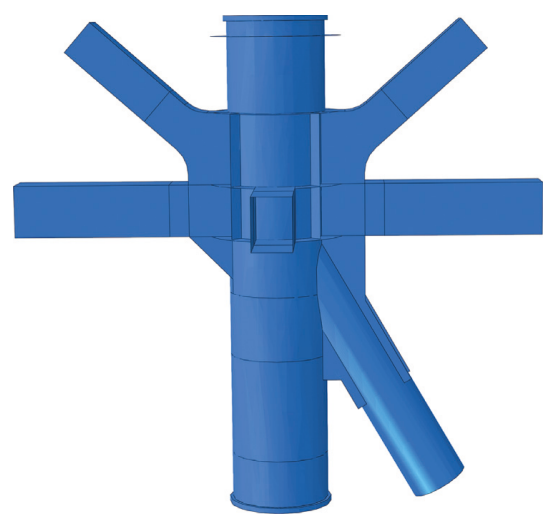

(a)

\section{$S$, Mises}

SNEG, $($ fraction $=-1.0)$

(Avg: 75\%)
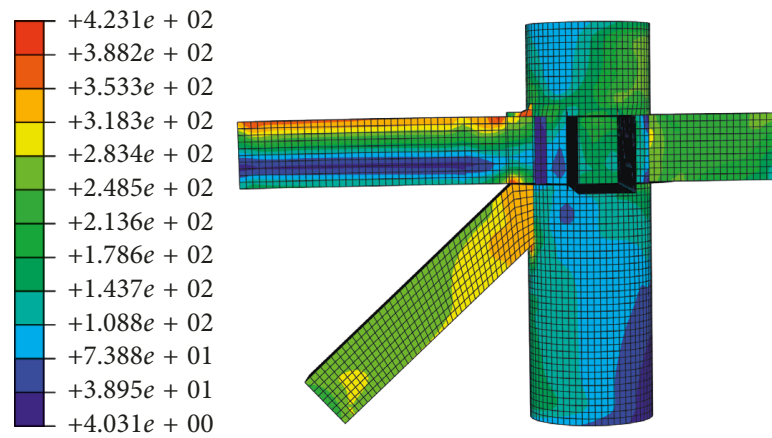

(c)
S, Mises

SNEG, $($ fraction $=-1.0$ )

(Avg: 75\%)
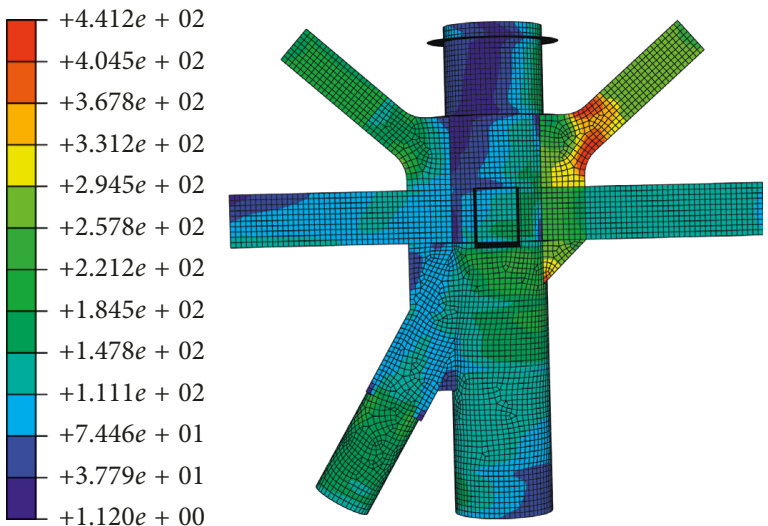

(b)

SNEG, $($ fraction $=-1.0)$

(Avg: $75 \%$ )

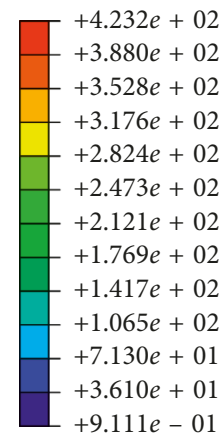

$+9.111 e-01$

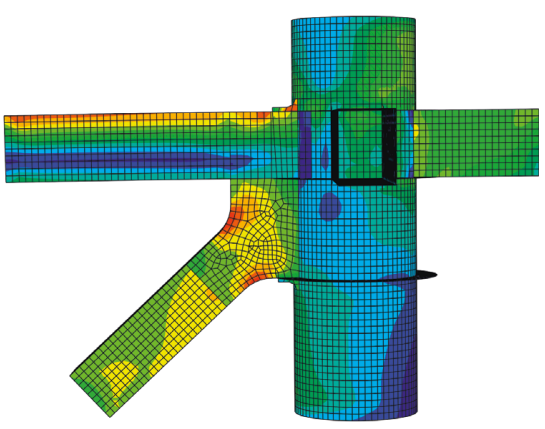

(d)

FIGURE 17: Stress nephogram of optimized A1 and A2 joint. (a) Final optimized joint form (b) Stress nephogram of optimized A1 joint. (c) Stress nephogram of initial A2 joint (d) Stress nephogram of optimized A2 joint.

S, Mises

SNEG, $($ fraction $=-1.0)$

(Avg: $75 \%)$

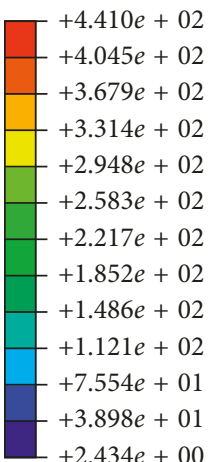

S, Mises

SNEG, $($ fraction $=-1.0)$

(Avg: $75 \%)$

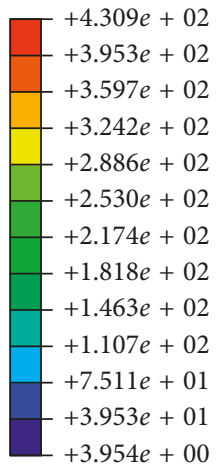

$+3.954 e+00$

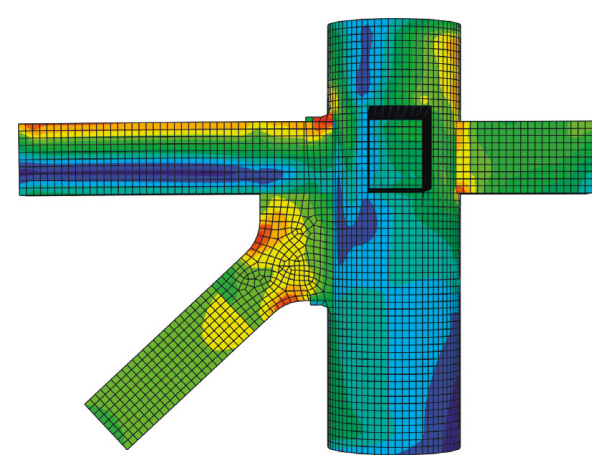

(b)

FIgURE 18: FE results of joint without outer diaphragm. (a) A1 joint. (b) A2 joint. 


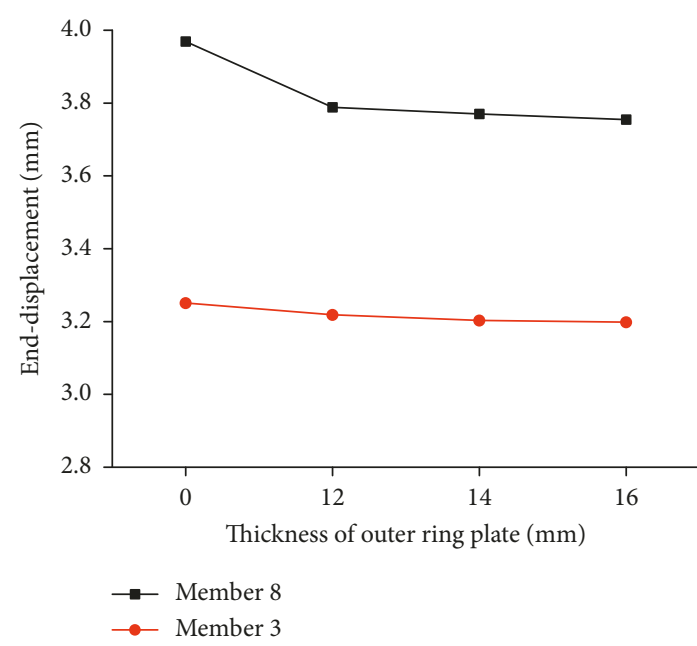

(a)

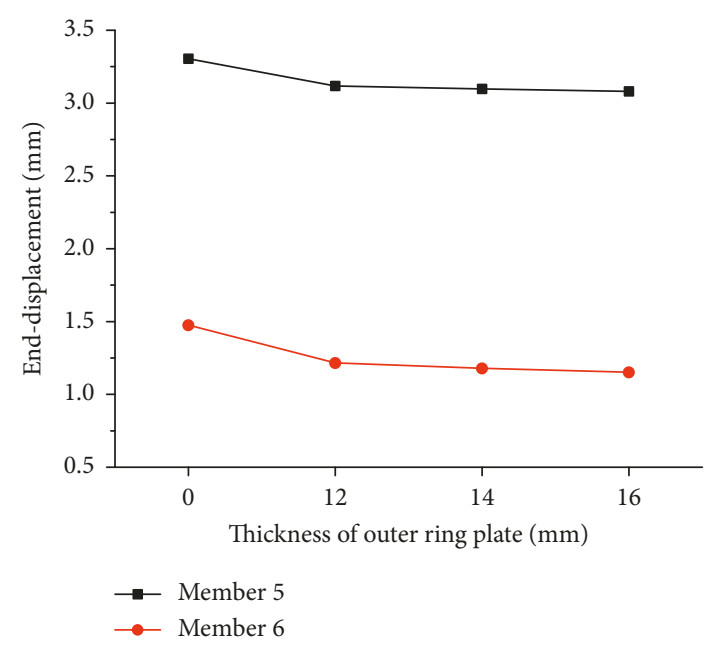

(b)

FIgURE 19: Beam member end-displacement and thickness curve. (a) A1 joint. (b) A2 joint.

tensile force and moment which can provide design guidance for other similar structures.

5.3.2. Outer Diaphragm. The outer diaphragm has been widely used in beam to CFT column joints, and internal force including moment and shear force of the beam member can be transferred to the CFT column effectively. It can also work well with the steel tube and increase the stiffness of the CFT column. In terms of seismic performance, the outer diaphragm can improve the ductility and strengthen the core area of the column joint. Based on the above considerations, FE models of three different types of joint form are established to investigate the influence of outer diaphragm on the mechanical performance of joints. Figure 18 shows the FE results of A1 and A2 joints without outer diaphragms under load case LS1 with 2.0-times design load. Figures 17(b) and 17(d) show the FE results of two joints within outer diaphragm. Comparing the stress nephogram of the joints, the stress of the joints without outer diaphragm in the core area of the steel tube wall increases slightly because strengthening measures already exists inside the CFT column. For the A1 joint, inner diaphragm with vertical stiffeners is used. For the A2 joint, the members penetrate through the CFT column to improve the tensile bearing capacity.

In addition, the influence of different outer diaphragm thickness on end-displacement of the beam member is also studied, and the displacement of the CFT column that considered as beam support is neglected in this investigation. According to Chinese code [14], the minimum thickness of outer diaphragm should not be less than the thickness of beam flange $(12 \mathrm{~mm})$, so outer diaphragms with four different thickness of $0 \mathrm{~mm}$ (means without outer diaphragms), $12 \mathrm{~mm}, 14 \mathrm{~mm}$, and $16 \mathrm{~mm}$ are analyzed under 2.0-times design load case LS1. Figure 19 shows FE results of the enddisplacement and thickness curve of $\mathrm{A} 1$ and $\mathrm{A} 2$ joints. It can be noted that the end-displacement of all beam members of A1 and A2 joint decreases after adding outer diaphragm. Especially for the individual beam member 3 of the A1 joint and member 6 of the A2 joint in the secondary plane, the enddisplacement is significantly reduced which means the outer diaphragm can effectively improve the rigidity of beam joint, and the results are consistent with the conclusion of other research [7]. However, as the thickness of outer diaphragm increases, the end-displacement of beam member decreases slightly and almost remains constant, which indicates that the influence of thickness on beam stiffness is limited when the thickness of outer diaphragm exceeds $12 \mathrm{~mm}$. Thus, the thickness of outer diaphragms is set to $12 \mathrm{~mm}$ which is the same as the thickness of beam flange.

\section{Conclusions}

In this paper, test and numerical studies on monotonic behavior of steel truss-to-concrete-filled tubular column joints were conducted. The following conclusions can be drawn:

(1) For two different load cases LS1 and LS2 under 1.0times design load, all the members of three joints are at the elastic stage and have a low stress level. Under 2.0-times design load, although few truss members enter the plastic stage, three joints all remain intact and have no large deformation. Test results prove the adaptability of three joints in structural design and all the three joints have a good safety reserve.

(2) Failure mode and test phenomena of three joints are illustrated in detail, and the main failure mode is the local buckling in the root region of steel truss member, and all CFT columns remain intact. The finite element method is also adopted to analyze the performance of joints, and the FE results of stress distributions are in good agreement with test results, which further prove the design conception of "strong column and weak beam."

(3) Considering the joints are the spatial specimen, the innovative three-dimensional connection subassembly 
testing system was described, and different support conditions of the A1 joint are analyzed by the FE method to facilitate the test system. Results show that when members 4, 5, 6, and 9 are set as fixed ends, the specimen is beneficial for both design load simulation and test operation.

(4) Design conception of proposed overlap joint form is analyzed, and the influence of different fillet radius in the transition region is described in detail. Compared with traditional N-type overlap joint, FE results show that the enlargement fillet radius and end area of the truss member can reduce the local compression effect and stress concentration, thus proving the adaptability of proposed overlap joint form.

(5) The influence of the outer diaphragm on the mechanical performance of the joint is further investigated. Different outer diaphragm thickness of the A1 joint is modeled and analyzed by the FE method, and results show that the outer diaphragm can increase the stiffness of the beam member. It is suggested to select the thickness of beam flange as that of outer diaphragm.

In general, the joint form and their design conceptions can provide good guidance for designers and engineers.

\section{Data Availability}

The data used to support the findings of this study are all included in the article.

\section{Conflicts of Interest}

The authors declare that they have no conflicts of interest.

\section{References}

[1] L.-H. Han, G.-H. Yao, and Z. Tao, "Behaviors of concretefilled steel tubular members subjected to combined loading," Thin-Walled Structures, vol. 45, no. 6, pp. 600-619, 2007.

[2] J. Pan, P. Wang, Y. Zheng, Z. Wang, and D. Liu, "An analytical study of square CFT columns in bracing connection subjected to axial loading," Advances in Civil Engineering, vol. 2018, Article ID 8618937, 15 pages, 2018.

[3] A. Elremaily and A. Azizinamini, "Experimental behavior of steel beam to CFT column connections," Journal of Constructional Steel Research, vol. 57, no. 10, pp. 1099-1119, 2001.

[4] M. M. A. Khanouki, N. H. Ramli Sulong, M. Shariati, and M. M. Tahir, "Investigation of through beam connection to concrete filled circular steel tube (CFCST) column," Journal of Constructional Steel Research, vol. 121, pp. 144-162, 2016.

[5] C. Vulcu, A. Stratan, A. Ciutina, and D. Dubina, "Beam-toCFT high-strength joints with external diaphragm. I: design and experimental validation," Journal of Structural Engineering, vol. 143, no. 5, Article ID 04017001, 2017.

[6] D. Zhang, S. Gao, and J. Gong, "Seismic behaviour of steel beam to circular CFST column assemblies with external diaphragms," Journal of Constructional Steel Research, vol. 76, pp. 155-166, 2012.
[7] Z. Q. Wang and J. C. Zhao, "Nonlinear FEM analysis of steel beam to steel tubular column connections with external stiffening rings," China Offshore Platform, vol. 26, no. 1, pp. 31-36, 2011, in Chinese.

[8] J. M. Ricles, S. W. Peng, and L. W. Lu, "Seismic behavior of composite concrete filled steel tube column-wide flange beam moment connections," Journal of Structural Engineering, vol. 130, no. 2, pp. 223-232, 2004.

[9] W. Tizani, Z. Y. Wang, and I. Hajirasouliha, "Hysteretic performance of a new blind bolted connection to concrete filled columns under cyclic loading: an experimental investigation," Engineering Structures, vol. 46, pp. 535-546, 2013.

[10] Y. Sakai, T. Hosaka, A. Isoe, A. Ichikawa, and K. Mitsuki, "Experiments on concrete filled and reinforced tubular K-joints of truss girder," Journal of Constructional Steel Research, vol. 60, no. 3-5, pp. 683-699, 2004.

[11] Eurocode 3 (EC3), Design of Steel Structures-Part 3-8: Design of Joints, EN1993-1-8, CEN, Brussels, Belgium, 2005.

[12] Eurocode 4 (EC4), Design of Composite Steel and Concrete Structures-Part 1-1: General Rules for Buildings, EN1994-1-1, CEN, Brussels, Belgium, 2004.

[13] J. A. Packer, J. Wardenier, X. L. Zhao, G. J. van der Vegte, and Y. Kurobane, Design Guide for Rectangular Hollow Section (RHS) Joints under Predominantly Static Loading, CIDECT, Geneva, Switzerland, 2009.

[14] CECS28:2012, Technical Specification for Concrete-Filled Steel Tubular Structures, National Standard of the People's Republic of China, Beijing, China, 2012, in Chinese.

[15] Y. J. Lou, L. W. Tong, E. Xie, G. Hou, Y. Y. Chen, and Z. M. Yin, "Experimental study on behavior of steel trussCFST column joints in Hongqiao station for high-speed railway," Progress in Steel Building Structures, vol. 12, no. 6, pp. 19-24, 2010, in Chinese.

[16] J. Fan, Q. Li, J. Nie, and H. Zhou, "Experimental study on the seismic performance of $3 \mathrm{D}$ joints between concrete-filled square steel tubular columns and composite beams," Journal of Structural Engineering, vol. 140, no. 12, article 04014094, 2014.

[17] Z. Li, W. Wang, Y. Chen, and T.-M. Chan, "Test and analysis on the seismic performance of a steel truss-to-circular CFT column sub-assembly," Journal of Constructional Steel Research, vol. 103, pp. 200-214, 2014.

[18] L. Tong, X. Wang, Y. Cheng, M. Gu, Z. Fan, and Y. Peng, "Experimental study on KK-joint between two welded square hollow section trusses in the national Stadium," Journal of Building Structures, vol. 28, no. 2, pp. 49-53, 2007.

[19] Z. Tian, Y. Liu, L. Jiang, W. Zhu, and Y. Ma, "A review on application of composite truss bridges composed of hollow structural section members," Journal of Traffic and Transportation Engineering (English Edition), vol. 6, no. 1, pp. 94108, 2019.

[20] Y. L. Xu, Experimental study on bonding behavior between deformed bar and concrete, Ph.D. thesis, Tsinghua University, Beijing, China, 1990, in Chinese.

[21] J. Wang, S. Afshan, N. Schillo, M. Theofanous, M. Feldmann, and L. Gardner, "Material properties and compressive local buckling response of high strength steel square and rectangular hollow sections," Engineering Structures, vol. 130, pp. 297-315, 2017.

[22] L. Vieira, R. Gonçalves, and D. Camotim, "On the local buckling of RHS members under axial force and biaxial bending," Thin-Walled Structures, vol. 129, pp. 10-19, 2018. 
[23] GB50017-2017, Code For Design of Steel Structures, National Standard of the People's Republic of China, Beijing, China, 2018, in Chinese.

[24] Y. Chen, J. Wan, K. Hu, J. Yang, and X. Chen, "Stress concentration factors of circular chord and square braces K-joints under axial loading," Thin-Walled Structures, vol. 113, pp. 287-298, 2017.

[25] J. A. Packer, F. R. Mashiri, X. L. Zhao, and S. Willibald, "Static and fatigue design of CHS-to-RHS welded connections using a branch conversion method," Journal of Constructional Steel Research, vol. 63, no. 1, pp. 82-95, 2007. 


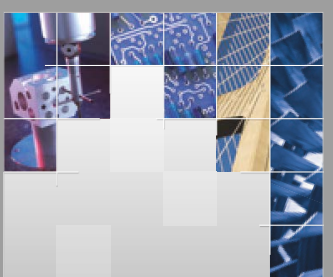

\section{Enfincering}
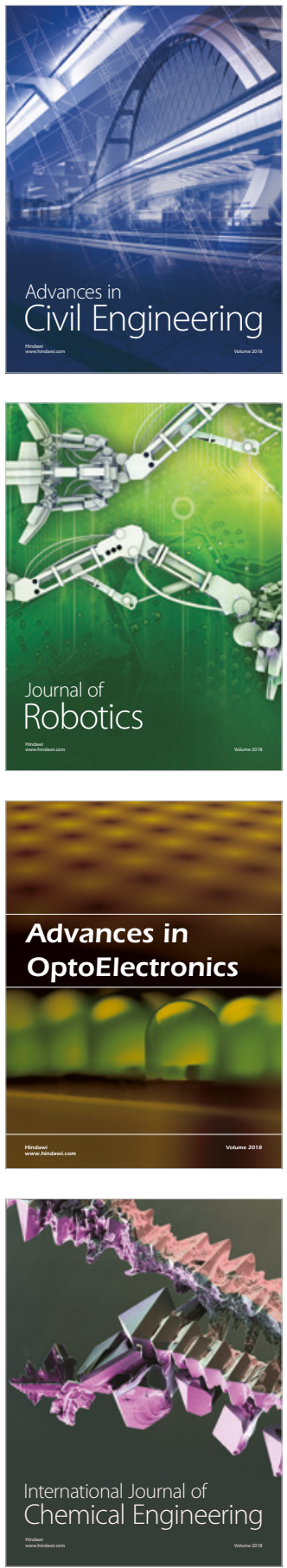

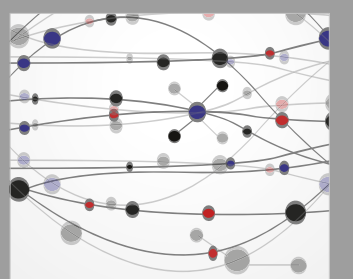

\section{Rotating \\ Machinery}

The Scientific World Journal

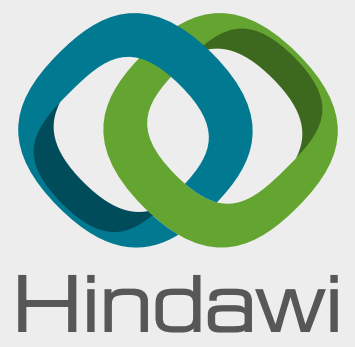

Submit your manuscripts at

www.hindawi.com
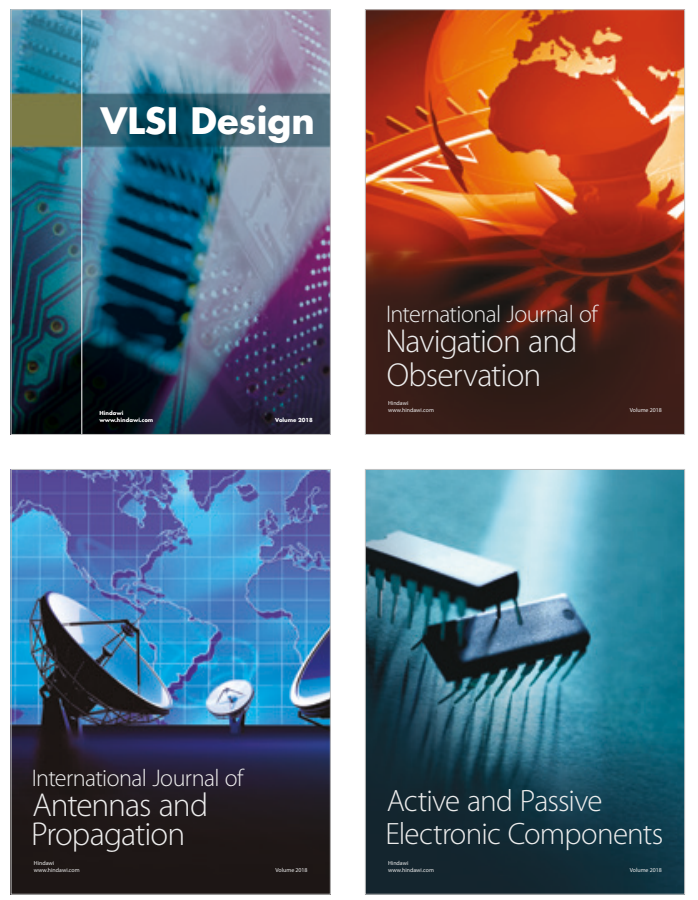
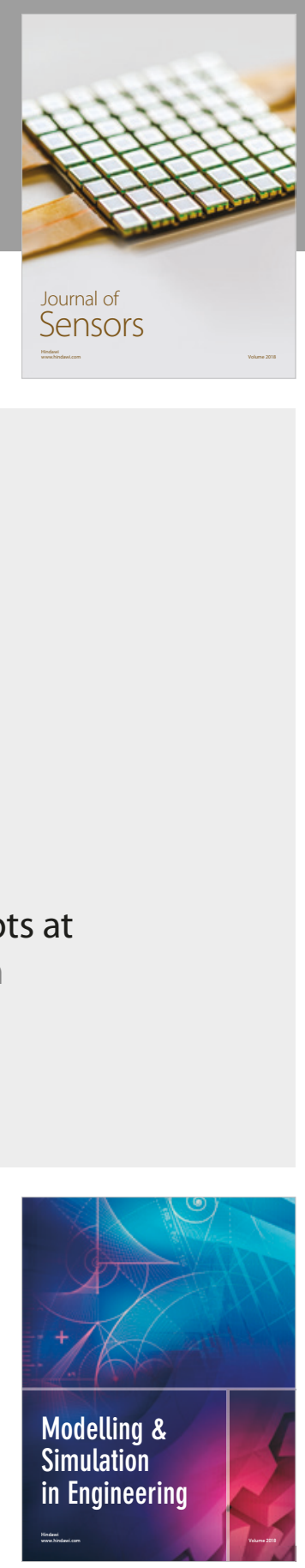

\section{Advances \\ Multimedia}
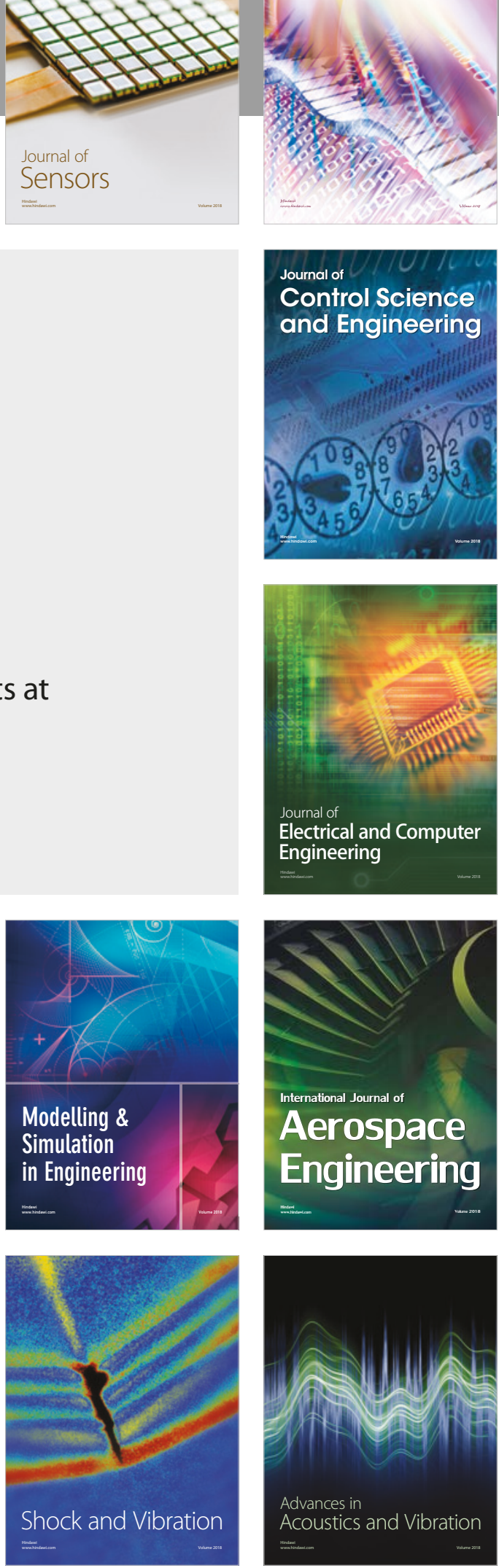